\title{
Study -"Comparative Study of Combined Spinal Epidural Versus Epidural Anaesthesia in Lower Limb Surgeries And Lower Abdominal Surgeries"
}

\author{
Dr. Shiv Sundar ${ }^{1}$, Dr. Mundwadkar ${ }^{2}$ \\ ${ }^{I}$ Chakraborty (Post Graduateresident Anaesthesia) \\ ${ }^{2}$ P.G.(Professor Ofanaesthesiology ,Svmch \& Rc Puducherry)
}

\begin{abstract}
Background: Epidural and spinal blocks are major techniques with long history of effective use for various surgeries and pain relief. Nevertheless, both technique have their drawbacks. Major disadvantage of subarachnoid blockade is precipitous hypotension and inability to obtain desired level. Epidural blockade with catheter insitu provides better control of analgesia and postoperative care. Although it has its own demerits like slower onset, large dose of local anaesthetic drug requirement, patchy anaesthesia. Combined spinal epidural techniques combines both features of subarachnoid block and continuous epidural anaesthesia. Purpose of this study is to compare combined epidural spinal technique with epidural alone technique in terms of onset, quality of analgesia, muscle relaxation and hemodynamic responses.
\end{abstract}

Objectives:

To compare CSE \& Epidural block alone in terms of

1) Total dosage of local anesthetic agents required

2) Degree of muscle relaxation obtained

3) Hemodynamic responses

4) Onset and duration of analgesia

5) Quality of analgesia

Methodology: Total of 60 patients were studied, 30 in each group ie group $C$ to whom combined spinal epidural was given and group E to whom only epidural block with catheter insitu was given. Onset of surgical analgesia was evaluated by skin prick method and quality of muscle relaxation was scored according to Bromage scoring, and quality of analgesia was evaluated by need of any other supplementary analgesic drugs. Patients hemodynamic parameters like blood pressure, heart rate and oxygen saturation was simultaneously recorded. Data was analyzed using the SPSS version 20.

Results \& Conclusion:

The study revealed the following

* Majority in both of the groups were in the age group of 51-60 years and there were no cases below 20 years in $C$ group while there were no cases above 60 years in $E$ group.

* The mean onset time and duration of analgesia in group C is very significantly shorter than in group $E$.

- The total amount of bupivacaine required to reach at the same level was approximately 3 times in the group $E$ as compared to group $C$ which is statistically significant with $p$ value $<0.001$.

* Majority of the patients who were given CSE had good quality of analgesia when compared to epidural route alone. This relationship is very significant in the C group with $p$ value $<0.001$.

- All the patients in group C had grade 3 blockade as compared to none in group E. And almost $70 \%$ of the grade 1 blockade was seen in group $E$ as compared to none in group $C$. Which signifies the superiority of CSE over Epidural alone.

* Systolic blood pressure change during anesthesia in both the groups shows overall p-value (almost all $p>0.05$ ) shows there no difference between the two groups which is statistically significant

* Diastolic blood pressure changes during anesthesia shows that overall p-values (almost all p>0.05) there is no difference between the two groups which are statistically significant.

* Pulse rate changes during anesthesia in both the groups shows that there is no difference between the two groups which is statistically significant with overall p-values (almost all $p>0.05$ )

* Mean respiratory rate changes during anesthesia in both the groups shows that there no difference between the two groups which are statistically significant with overall $p$-values (almost all $p>0.05$ )

Keywords: Epidural, combined spinal epidural, bupivacaine, analgesia 


\section{Introduction}

"Pain is an unpleasant sensory and emotional experience associated with actual or potential tissue damage, or described in terms of such damage."

The International Association for the Study of Pain Pain is unpleasant and noxious stimulus which is associated with fear and anxiety. All lower limb \& lower abdominal surgeries have been performed under various regional anesthesia's such as subarachnoid block, epidural or, combination of both each method has their own demerit \& merit.Major disadvantages of spinal block are precipitous hypotension and difficulty in controlling the level of analgesia ${ }^{2}$. Epidural block with the catheter technique gives a better control of the level of analgesia and also can be used for providing post-operative pain relief by. But, slower onset of action, patchy anesthesia, more doses of local anesthetics and hazard of cardiovascular and neurotoxicity are its drawbacks. The combined spinal-epidural technique (CSE) can be defined as the intentional injection of drug into the subarachnoid space and the placement of a catheter into the epidural space as part of the same procedure. The CSE technique involves injection low dose of subarachnoid local anesthetic and then extension of block by injecting drug through the epidural Catheter and aims to provide the benefits of spinal block with the flexibility of an indwelling epidural catheter to extend the duration of analgesia into the postoperative period. It was introduced by Soresi in 1937 using "single needle - single interspace" technique ${ }^{4}$. Later on, various modifications and different methods came into use, each having some advantages over the other. However, the first combined spinal anaesthesia and catheter-based epidural anaesthesia was performed by Curelaru in 1979.

Major surgeries below the umbilical level requires excellent surgical conditions and prolonged and effective postoperative analgesia. Where in combined spinal epidural anesthesia (CSE) has been proposed as an alternative technique to standard spinal anesthesia (SA) ${ }^{6}$. CSE technique provides better surgical conditions than with epidural block alone.Combined Spinal Epidural Anaesthesia (CSE) combines two techniques which has greater efficacy \& cost effectiveness. The benefit of this technique lies in its ability to combine the rapidity, density, and reliability of the subarachnoid block with the flexibility of continuous epidural block to titrate a desired sensory level, vary the intensity of the block, control the duration of anesthesia, and deliver postoperative analgesia.Although various other methods are available for postoperative \& intraoperative analgesia, such as pharmacological \& regional blocks. Use of high dose of pain medication endangers the patient vital organs such as renal and liver and also increases the total cost of delivering prudent anaesthesia. Use of more recent technique such as lumbar block, celiac block, paracervical block is more technically challenging and further requirement of higher imaging techniques for identifying the anatomy is difficult in many setting, and especially in our country. Therefore, CSE technique need further study in Indian patients in order to have a depth of understanding that in which surgeries and in which set of patients it will be benefited. Which made us to take up this study to compare CSE \&Epidural block alone in terms of onset and duration of surgical analgesia.

Aim Of The Study

\section{Aim And Objectives}

Aim of this study is to compare CSE \& Epidural block alone in terms of onset and duration of surgical analgesia.

\section{Objectives}

To compare CSE \& Epidural block alone in terms of

- Total dosage of local anesthetic agents required

- Degree of muscle relaxation obtained

- Hemodynamic responses

- Onset and duration of analgesia

- Quality of analgesia

\section{Review of literature Anatomy of vertebral canal \& epidural spaceVertebral canal}

The vertebral canal extends from foramen magnum to sacral hiatus. Composed of 33 vertebrae ( 7 cervical, 12 thoracic, 5 lumbar, 5 fused sacral, 4 coccygeal). It has 4 curves; cervical \& lumbar curves are convex anteriorly while thorax \& sacral curves are convex posteriorly. These curves have a significant influence on the spread of local anesthetic in subarachnoid \& epidural space The canal is bounded in front by bodies of the vertebrae \& intervertebral disc with posterior longitudinal ligament, posteriorly by the laminae \& ligamentum flava, laterally by pedicle \& laminae. The vertebral canal is narrow at the thoracic level \& considerably wider at cervical \& lumbar level.

The vertebral column is bounded together by several ligaments which gives its stability \& elasticity

1. Supraspinous ligament

2. Interspinous ligament 
3. Ligamentum flavum

4. Longitudinal ligaments

a) Supraspinous ligament: it is a strong fibrous ligament that connects the apices of the spinous processes from the sacrum to $\mathrm{C}$, where it is continued upwards to the external occipital protuberance as the ligamentum nuchae. It is thickest \& broadest in the lumbar region \& varies with patient's age \& sex.

b)Interspinous ligament: it is a thin membranous ligament that connects the spinous process together, uniting the lower border of one with the upper border of its caudal neighbor. Therefore, the ligament is rectangular in shape. It blends anteriorly with the ligamentum flavum \& posteriorly with supraspinatous ligament.

c) Ligamentum flavum: the ligament is composed of yellow elastic fibers \& connects adjacent laminae that run from the caudal edge of vertebra above to the cephalad edge of lamina below, laterally this ligament begins at the roots of the articular processes \& extends posteriorly \& medially to the point where the laminae join to form the spinous process. Here the two components of the ligaments are united, thus covering the interlaminar space

They cover the capsule of articular facets, the lower part of the upper laminae \& the interlaminar spaces. The ligamentum flava constitute slightly more than half of posterior wall of the vertebral canal. They are thickest \& strongest in the lumbar region where powerful stresses \& strain have to be countered. Site thickness of ligamentum flava:

1)Cervical 1.5 to $3 \mathrm{~mm}$

2) Thoracic 3 to $5 \mathrm{~mm}$

3) Lumbar 5 to $6 \mathrm{~mm}$

4) Sacral 2 to $6 \mathrm{~mm}$

d) Longitudinal ligament: anterior \& posterior longitudinal ligaments bind the vertebral bodies together

\section{Posterior longitudinal ligament:}

Lies within canal on posterior surface of bodies of vertebra from which it is separated by basivetebral veins. This ligament is thinnest in cervical \& lumbar region.

Anterior longitudinal ligament: it is more of anatomic interest than that of anesthetic importance, it runs along the front of vertebral bodies.

The cervical, thoracic \& lumbar vertebra have certain differentiating features. Cervical vertebra differs from the thoracic \&lumbar vertebra, the former have foramina in their transverse process. The thoracic vertebra has articular facets for ribs on their bodies. The spine of the thoracic vertebra slopes downward while spine of lumbar vertebra is more horizontal.

\section{Lumbar vertebra:}
A typical lumbar vertebra is made up of following parts:
1. The body
2. Vertebral arch
3. Transverse \& spinous processes
4. Superior \& inferior articular processes

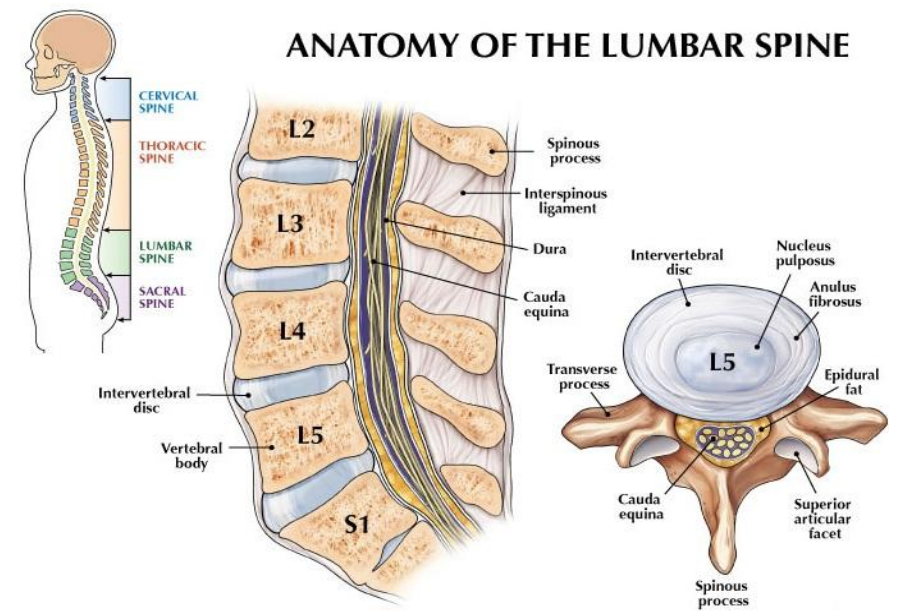

Fig 1: Anatomy of lumbar spine. 


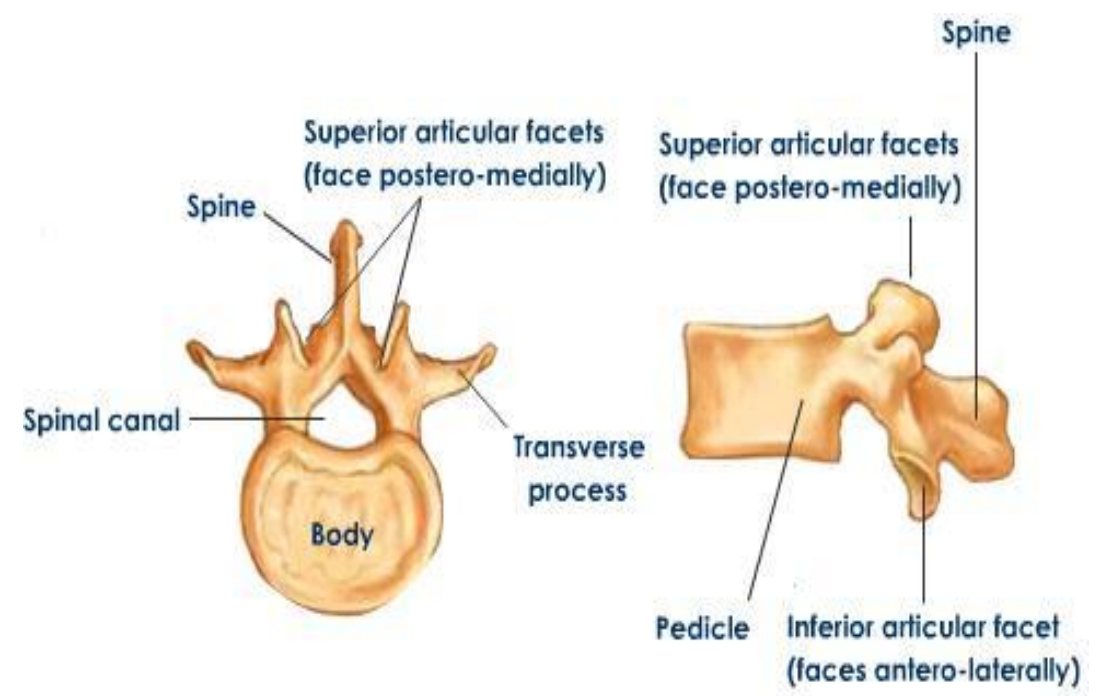

Fig 2: Anatomy of lumbar vertebra.

Body:

It is kidney shaped. They are weight bearing. The flat articular surfaces are covered with hyaline cartilage, which is firmly united to the fibrocartilagenous intervertebral disc (annulus fibrosus \& nucleus pulposus). The anterior \& posterior longitudinal ligaments reinforce the union between the bodies. The broad anterior longitudinal ligaments are firmly attached to the intervertebral discs \& loosely attached to bodies. The posterior longitudinal ligament is narrower \& is similarly attached. It sends a few irregular slender fibers to join the anterior surface of the spinal duramater.

\section{Vertebral arch:}

Composed of pedicles \& laminae which surround \&protect the spinal cord \& its coverings. Each half of the vertebral arch is divided into two parts by the root of the transverse process. Anteriorly the arch is formed by the powerful rounded pedicle, whose function is to transmit stress. Posteriorly it is completed by the lamina, which is flat $\&$ is mainly protective in function. From vertebral arches four articular processes project, of which two are directed upwards \& two downwards to articular processes project, of which two are directed upwards \& two downwards to articulate with similar processes of the adjacent vertebra.

The superior articular processes spring from the junctions of pedicles \& laminae. They project upwards behind the pedicles \& come to lie just above the level of transverse processes $\&$ the articular facets on their posterior surface facing backwards \& medially. The inferior articular processes extend downwards from the inferolateral aspects of the laminae. They lie well below the level of transverse processes \& the articular facets on their anterior surface are placed laterally $\&$ forwards. So that they articulate with the facets on the superior articular processes of the vertebra below.

The pedicles arise from the upper part of the posterolateral surface of the body. So that there are two notches formed between the body \& the pedicle viz, superior \& inferior of which inferior is much deeper. So when two adjacent vertebra articulate they enclose an intervertebral foramen on either side through which the mixed spinal nerve of that particular segment issues. The boundaries of the intervertebral foramen are bounded superiorly \& inferiorly by the pedicles of adjoining vertebra, posteriorly the capsules surrounding the articular processes of adjoint vertebra and anteriorly by the intervertebral disc and the lower part of the body above it. Posterior surface of vertebral body and arch form boundaries of vertebral foramen. Vertebral foramen contains the spinal cord and its membranes. Anterior surface formed by body and disc with posterior longitudinal ligament. Laterally, intervertebral foramen is present which allows segmental spinal nerves to pass. Posteriorly interlaminar foramina is present through which subarachnoid and epidural spaces are approached.

In the lumbar spaces interlaminar foramina is small when patient extends his spine. When asked to flex his spine these foramina become big and diamond shaped, anatomically these foramina is guarded by, at the base by upper lamina of vertebra below and sides by medial aspect of inferior articular process of vertebra above

\section{Intervertebral disc:}

In the cervical and lumbar region these disc is wedge shaped thus giving characteristic curves of the column. In lumbar region they are thickest. They have annulus fibrosus attached to hyaline cartilage at the articular surfaces. Annulus contains nucleus pulposus which are gelatinous material and changes its shape during the movements. Nucleus pulposus acts both as shock absorber and provide flexibility to the spine. During flexion injury and faulty lumbar puncture annulus may rupture especially posteriorly and nucleus pulposus may 
herniate. This phenomenon is called disc prolapse which causes radiating pain at lower limb and back depending on nerve roots involved.

\section{Intervertebral foramen}

These foramina allow the spinal nerve roots with vessels to pass through it. In elderly patient this foramen has dense tissue and in young patient they have loose areolar tissue, so dosage of drug needed for elderly is less compared to young patients.

\section{Spinal meninges}

Spinal cord is protected by three connective tissue covering the meninges

\section{Dura mater:}

Tough fibro elastic tube fibers running longitudinally. It can be described in cranial and spinal part. It is attached to foramen magnum. Outer endosteal layer of cranial duramater become continues with vertebral layer. Inferiorly dura mater ends as dural sac at lower border of S2. The filum terminale helps to anchor the tip of spinal cord to periosteum, dura also provides cover for the nerves. The nerves are covered by dural sleeves which continues till spinal ganglion then perineurium replaces them. Thickness of dura is more in the posterior region than anterior especially in the midline therefore Tuohy needle rarely punctures dura.

\section{Arachnoid mater:}

It is one of middle covering among the three. It ends in S2 lower border, between arachnoid and dura lies subdural space which contains little serous fluid. The arachnoid villi and granulations penetrate dura mater and lie close to epidural veins, it helps to circulate csf from subarachnoid space.

\section{Pia mater:}

This membrane is vascular and enclose the spinal cord and brain, space between arachnoid and pia is called subarachnoid space. This contains CSF, spinal rootlet, trabeculae. Pia along with denticulate ligament attach to dura providing support to spinal cord.

\section{Nerve supply of meninges:}

When dura is pierced with spinal needle then pain is not felt because posterior part is not supplied by nerve, instead anterior part supplied by a pairs of nerve.

Spinal nerves:

Spinal cord lays down 31 pairs of symmetrically arranged spinal nerves.

Epidural space

The epidural space is one of the most explored spaces of the human body. This exploration demands a good knowledge of the relevant anatomy and contents of the space. First described in $1901{ }^{28}$, the epidural space is an anatomic compartment between the dural sheath and the spinal canal. In some areas it is a real space and in others only a potential space. The use of the term 'space' has been controversial amongst anatomists. It is argued that the term would be more appropriate for the subarachnoid space than the epidural. It is claimed that the epidural space is an open anatomical space whether in life or death. The only time space becomes bigger in dimension when the dura mater is artificially separated from the overlying vertebral canal by injection of contrast media or solutions of local anesthetics. The vertebral column is made up of 24 individual vertebrae comprising 7 cervical, 12 thoracic and 5 lumbar while 5 sacral vertebrae are fused and the 3-5 coccygeal bones, though fused, remain rudimentary. These vertebrae house the epidural and the subarachnoid spaces.

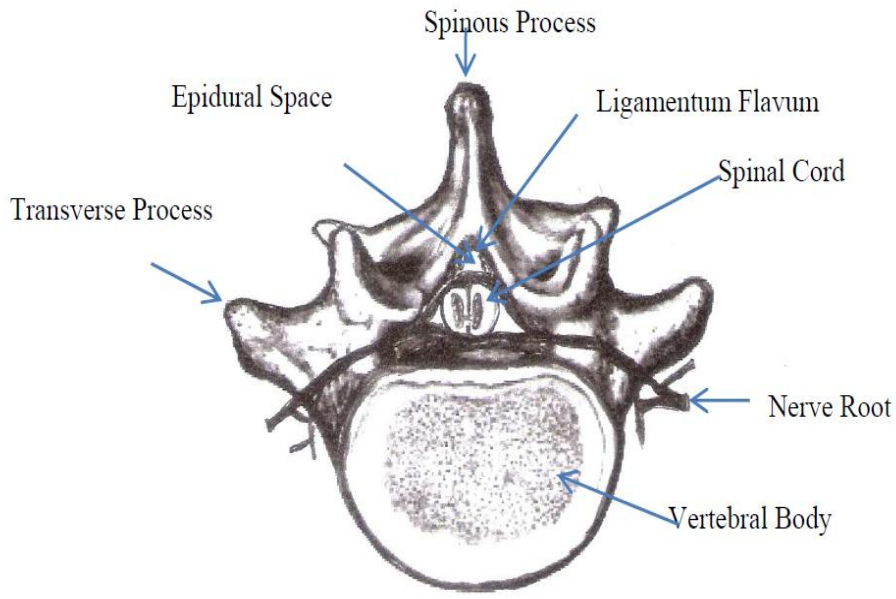

Transverse Section of the Lumbar Vertebra

Fig 3: Transverse section of lumbar vertebra. 


\section{Measurement of the epidural space}

The epidural space is roomiest at the upper thoracic levels. The epidural space at theposterior space in the adult measures about 1-1.5 $\mathrm{mm}$ at C7-T1, 2.5-3 $\mathrm{mm}$ in the upper thoracicregion, 4-5 $\mathrm{mm}$ at T11-12 region and $5-7 \mathrm{~mm}$ in the lumbar region.The space is far greater than that of the subarachnoid space at the same level. It takes about $1.5-2.0 \mathrm{ml}$ of a local anesthetic to block a spinal segment in the epidural space while thevolume $(0.3 \mathrm{ml})$ is far less in the subarachnoid space for a similar block. It has been shown ${ }^{31}$ that the paravertebral spaces, both serially and contra laterally,communicate with each other in the epidural space.

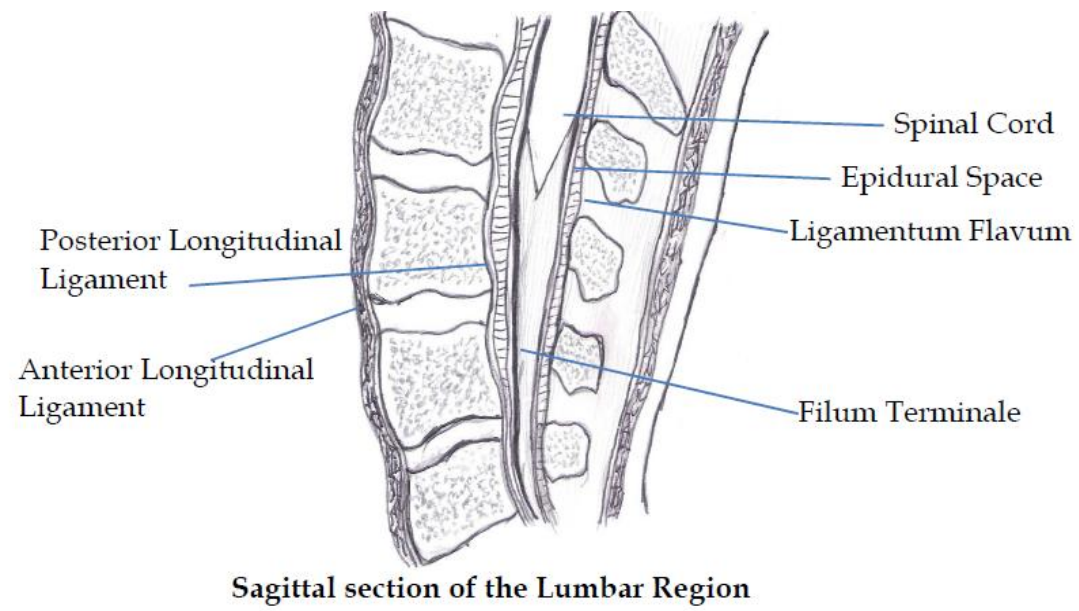

Fig 4: Sagittal section of lumbar region.

\section{Shape and size of the epidural space}

These are largely determined by the shape of the lumbar vertebral canal and the positionand size of the dural sac within it. It has been suggested that though merely a potentialspace ${ }^{32}$ it could be up to $5 \mathrm{~mm}$ in depth. ${ }^{33}$

\section{Types of epidural space}

The epidural space can be categorized into cervical, thoracic, lumbar and sacral epiduralspaces. These spaces can be defined according to their margins. At the cervical epiduralspace, there is a fusion of the spinal and periosteal layers of dura mater at the foramenmagnum to lower margin of the 7 th cervical vertebra. While the thoracic epidural space isformed by the lower margin of $\mathrm{C} 7$ to the upper margin of L1, the lumbar epidural space isformed by the lower margin of L1 vertebra to the upper margin of S1 vertebra. The sacralepidural space is formed by the upper margin of S1 to sacrococcygeal membrane.

\section{The contents of the epidural space}

This space contains semi-liquid fat, lymphatics, arteries, loose areolar connective tissue, thespinal nerve roots, and extensive plexus of veins. The epidural contents are contained in aseries of circumferentially discontinuous compartments separated by zones where the duracontacts the wall of the vertebral canal

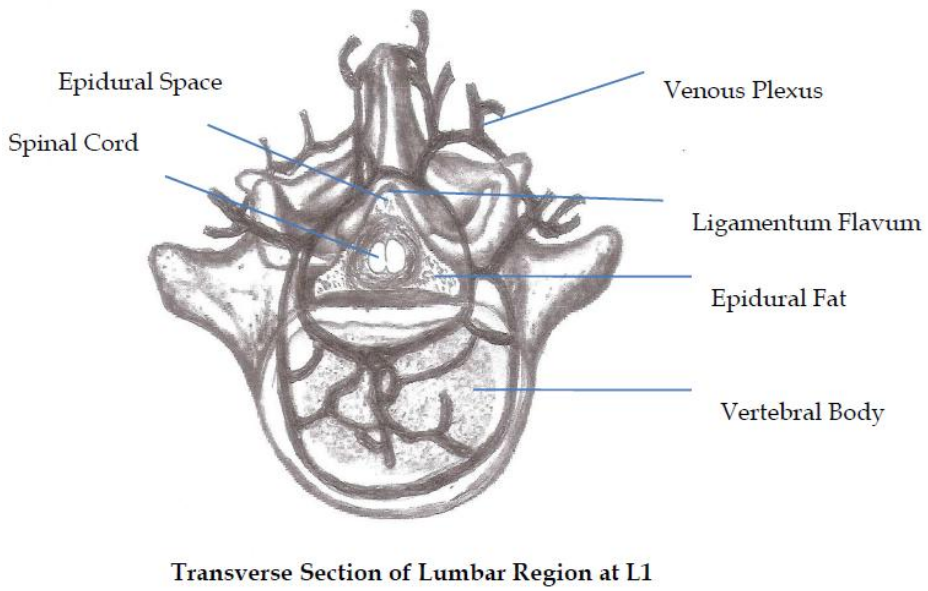

Fig 5: Transverse section of lumbar region at L1 


\section{Clinical importance of the epidural space}

The epidural space has been subjected to many clinical manipulations for purposes of anesthesia and analgesia. Injection into this space can be by a single shot, intermittent,continuous or under the control of the patient (Patient controlled epidural analgesia (PCEA)).

Intermittent or continuous injections into the space are carried out through an epidural catheter. The epidural space is catheterized in a wide range of clinical reasons.

\section{Identification of the epidural space:}

Identification of the epidural space is of crucial importance as it is technically demanding.The first demonstration of this space was about 78 years ago ${ }^{35}$. The accuracyin the location of the space however, determines the functionality of the epidural analgesia.The epidural needle, if inserted in the midline, pierces the skin and traverses thesubcutaneous tissue, supraspinous ligament, interspinous ligament and through theligamentum flavum to reach the space. The depth of the epidural space has been defined asthe distance from overlying skin to the tip of the needle just penetrating into the epiduralspace ${ }^{36}$. The depth can pose some difficulties during the location of theepidural space particularly in the obese patient.To improve the success rate, the distance from skin to the epidural space and its correlationwith body mass index (BMI) have been studied ${ }^{37}$. This study showed that asthe BMI increased, the depth of the epidural space increased significant. The study wasbased on a predictive equation of depth of epidural space from skin in relation to BMI basedon linear regression analysis as: Depth $(\mathrm{mm})=\mathrm{a}+\mathrm{b}(\mathrm{BMI})$. Where $\mathrm{a}=17.7966$ and $\mathrm{b}=0.9777 .^{37}$

\section{History}

The first epidural analgesia was done by Corning in $1885^{38}$. Lumbar dural puncture was introduced in 1891 by Wynter ${ }^{39}$ in England and Quincke ${ }^{40}$ in Germany. Von Ziemssen in $1894^{41}$ suggested the feasibility of injecting drugs by means of lumbar dural puncture. August Bier was the first to inject cocaine into the spinal space in $1898 .{ }^{42}$ Cocaine congeners such as norcocaine, pseudococaine, and tropacocaine, and isomers of phenyltropane analogs were later brought into practice from 1902.

It took 52 years since Corning`s discovery of the epidural analgesia and 39 years since Bier`s spinal anaesthesia that these two compartments were first combined by Soresi in 1937. ${ }^{4}$ It took another 42 years until Curelaru in 1979 used this combined spinal-epidural anaesthesia again. ${ }^{5}$ Cocaine was the first spinal anesthetic used, procaine and tetracaine soon followed.

Lidocaine was first used as a spinal anesthetic in 1945, and it has been one of the most widely used spinal anesthetics. Onset of anaesthesia occurs in 3 to $5 \mathrm{~min}$ with duration lasting for 1 to $1.5 \mathrm{~h}$. Lidocaine spinal anaesthesia has been used for short to intermediate length operating room cases, and the most common ampoule is $5 \%$ lidocaine in $7.5 \%$ dextrose. One drawback of lidocaine was its association with transient neurologic symptoms (TNS), which presents as low back pain and lower extremity dysesthesias with radiation to the buttocks, thighs, and lower limbs after recovery from spinal anaesthesia. TNS occurs in about $14 \%$ of patients receiving lidocaine spinal anaesthesia. ${ }^{43}$

Bupivacaine as a viable alternative to lidocaine for spinal anaesthesia has been used frequently with very little incidence of TNS. ${ }^{44}$ Onset of anaesthesia occurs in $8 \mathrm{~min}$ with a duration lasting from 210 to $240 \mathrm{~min}$. Tetracaine has an onset of anaesthesia within 3 to $5 \mathrm{~min}$ and a duration of 210 to $240 \mathrm{~min}$, and like bupivacaine, is used for cases that are intermediate to longer length. TNS occurs at a lower rate than with lidocaine spinal anaesthesia. The addition of phenylephrine may play a role in the development of TNS. ${ }^{45}$

Mepivacaine is very similar to lidocaine and has been used since the 1960s for spinal anaesthesia. The incidence of TNS reported after mepivacaine spinal anaesthesia varies widely, with rates from $0 \%$ to $30 \% .{ }^{46}$

\section{Combined Spinal Epidural Anesthesia and Analgesia}

Although CSE anesthesia was originally described for urological surgery, indications for itsuse have expanded in recent years. CSE is now widely used in obstetrics, orthopedic surgery, trauma, abdominal, vascular andgynecologic surgery ${ }^{5}$.

CSE anesthesia allows the use of very lowsubarachnoid drug doses, due to the synergistic interaction between subarachnoid andepidural drugs. The CSE anesthesia is very appropriate for outpatient surgery, because theblock wears off rapidly, so that patients ambulate earlier and can be discharged home sooner ${ }^{47,48,49}$. Contraindications to CSEanesthesia are the same as for any neuraxial blockade. 
Study - “Comparative Study Of Combined Spinal Epidural Versus Epidural .......

\begin{tabular}{ll}
\hline Surgery type & Surgical procedure \\
\hline Obstetrics & Labor analgesia, Cesarean Section \\
Gynecology & Hysterectomy \\
Orthopedics & Hip and knee surgery \\
Urology & Prostatectomy, cystectomy \\
Abdominal surgery & Colorectal, renal transplantation \\
Vascular surgery & Open surgical repair of infrarenal abdominal aortic \\
& aneurysm \\
Ambulatory surgery & Reconstructive surgery of lower extremities \\
Pediatric surgery & Knee arthroscopy \\
\hline
\end{tabular}

Table 1: Use of CSE in surgical practice

\section{CSE Techniques}

\section{Needle-through-needle technique:}

The first "spinal-needle-through-epidural needle" technique was described by Coates ${ }^{50}$. After the epidural space is identified using an epidural needle, theepidural needle serves as introducer, and a fine spinal needle is advanced through theepidural needle, beyond its tip, until it punctures the dura. Medications are first injected inthe subarachnoid space, and then the epidural catheter is inserted.

Disadvantages of this technique are the possibility for advancing the epidural catheter into the subarachnoidspace, and the possibility for needle damage from friction between the needles. Although itis possible to combine a plain Tuohy needle with a longer, thinner spinal needle forperforming the procedure, special commercial "all in one" kits have become available. Longthin needles make it more difficult to feel perforation of the dura; therefore, the "hangingdrop" technique is recommended to identify the spinal space after dura perforation. ${ }^{51}$

The "Hanging drop" technique consists of placing one drop ofnormal saline in the hub of spinal needle. This "hanging drop" will fall down from the hubof the needle when the spinal needle reaches the subarachnoid space.

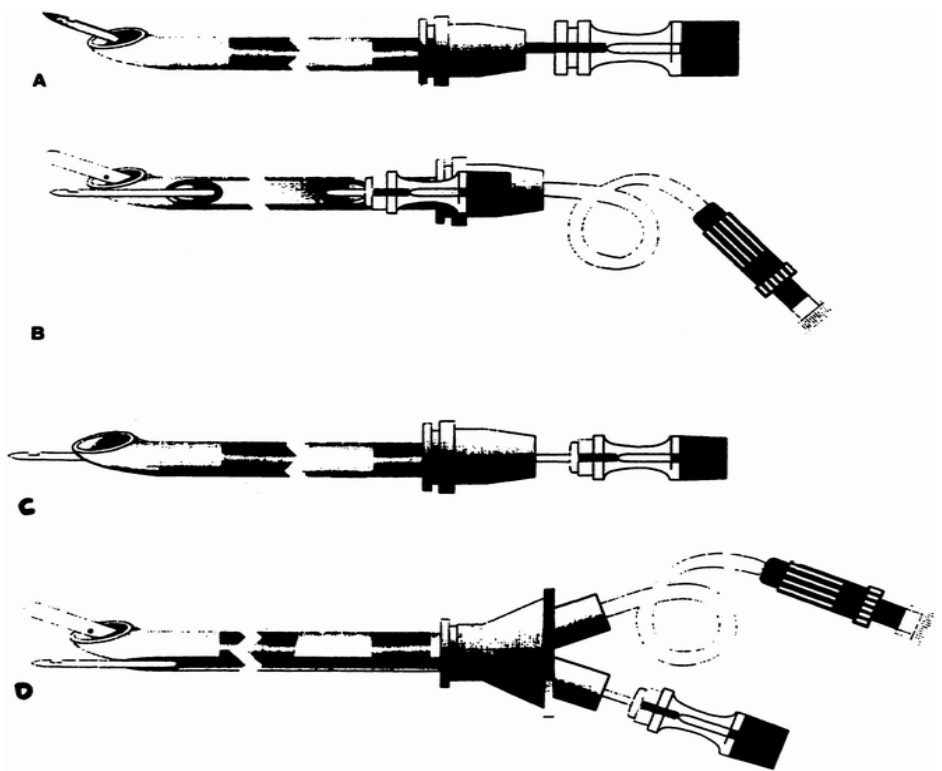

Fig 6: Needle-through-needle technique

\section{Separate needles:}

In this technique, the two components of CSE (spinal and epidural injection) are performedusing separate needles, in the same or at different inter-vertebral spaces, in either order ${ }^{52}$.Performing both the epidural and spinal injection at the same interspace requires infiltrationwith local anesthetic only once. When using this technique, the epidural needle is placedfirst, to serve as introducer for the spinal needle at the same interspace. Then, after theepidural catheter is advanced, the spinal needle is advanced in order to puncture the duraand allow the subarachnoid injection ${ }^{53}$. 
Study - “Comparative Study Of Combined Spinal Epidural Versus Epidural .......

When using thistechnique, epidural catheter damage caused with spinal needle during dural puncture is apossible complication. A modification of this technique, proposed by Cook, suggested thatthe spinal needle be placed as low as possible in the interspace, whereas the epiduralcatheter is placed cephalad, and then subarachnoid injection is performed ${ }^{54}$.

The technique using two different interspaces confers the advantage that it allows epiduralcatheter placement in the thoracic or the lumbar area, depending on the location of the pain, while the subarachnoid injection is still done in the lumbar area ${ }^{27}$. In addition, this technique allows the use of an epidural test dose to confirm appropriateplacement of the epidural catheter before the spinal injection, and avoids potential punctureof the epidural catheter by the spinal needle.

However, despite these presumed advantages, in the absence of robust evidence, expert opinion suggests that, compared to the separateinterspaces technique, the "needle-through-needle" technique causes "considerably less discomfort, trauma and morbidity from inter-spinous space penetration including backache,epidural venous puncture, hematoma, infection and technical difficulties" 55 .

\section{Special single CSE needles:}

The Eldor needle technique is a slightly different technique that was introduced in 1990, anduses a specialized needle for CSE. The Eldor needle is both spinal and epidural needle,combining an 18G epidural needle with a $20 \mathrm{G}$ spinal conduit, and the epidural catheter canbe introduced before the spinal injection. An image of the needle is available online at thecompany website.

Use of the Eldor needle reduces the risk of accidental subarachnoidplacement of the epidural catheter, and avoids friction of the needles and post-duralpuncture headaches. The Eldor needle is used as follows: First, the spinal needle isintroduced into the guide needle. Then, the Eldor needle is placed in the selected intervertebralspace, using the "loss of resistance" technique to locate the epidural space. Afterreaching the epidural space, the epidural catheter is inserted first, and then the spinal needleis advanced until it perforates the dura. Following the subarachnoid injection, the spinalneedle is removed, and then the Eldor needle is also removed.

The Coombs epidural -spinal needle is a newer multi-lumen device ${ }^{56}$ that hastwo different channels, with the spinal channel being underneath the epidural channel.However, despite their advantages, Eldor needles and Coombs needles have not gainedwidespread popularity because they are uncomfortably large ${ }^{50}$.A RCT comparing a CSE set with an interlocking device between the spinal and epiduralneedle vs. a CSE set with a "backeye" at the epidural needle curve for passage of the spinalneedle vs. the double-segment technique, showed that use of CSE sets does not save timecompared with the double segment technique ${ }^{57}$. Moreover, damagedspinal needle tips were noted relatively often with the interlocking CSE set.

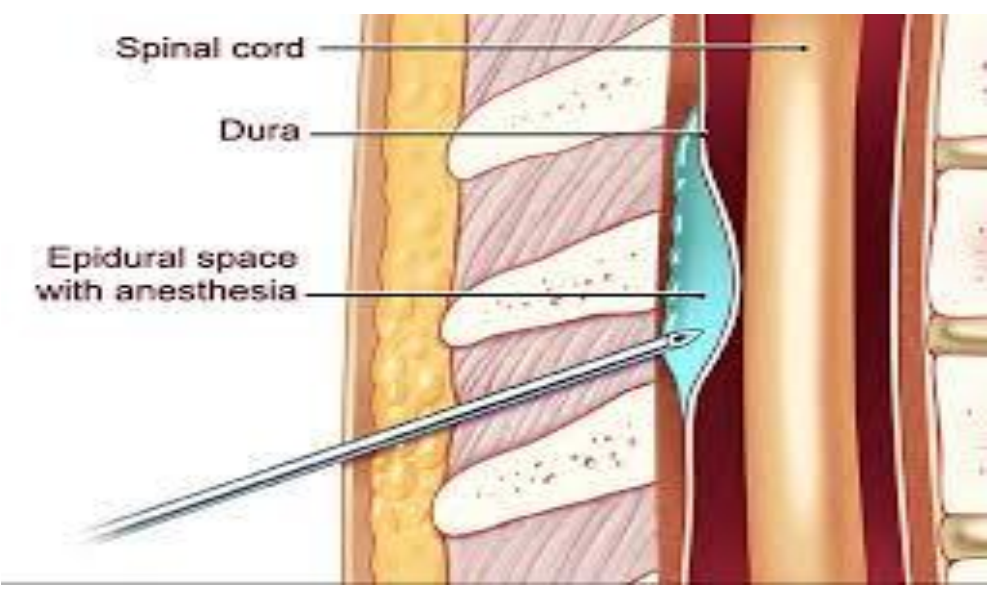

Fig 7: Special single CSE needles.

\section{Dual catheter technique}

The dual catheter technique involves the insertion of two catheters, one in the epiduralspace and one in the subarachnoid space on the same patient. Having both an epidural anda subarachnoid catheter confers certain advantages, in that both spinal anesthesia andepidural analgesia can be extended or prolonged, as needed for surgery and postoperativeanalgesia. However, having two similar catheters on the same patient introduces thepotential for serious errors, mainly the inadvertent subarachnoid injection of medications indoses intended for epidural use. Clearly, such errors could be life-threatening if not detectedearly. At the present time due to concerns about the risk of inadvertent epidural injection oflocal anesthetic through the subarachnoid, rather than through the epidural catheter, thedual catheter technique is rarely used ${ }^{58,59}$. 
Study - “Comparative Study Of Combined Spinal Epidural Versus Epidural ........

\section{Related Studies With Observations}

In the study conducted in 1997 by Michael p. Nageotte et al ${ }^{66}$ they found that There were no significant differences in the overall rate of cesarean section, the incidence of dystocia, the frequency of maternal or fetal complications, the patients' or nursing staff's assessment of the adequacy of analgesia, or the degree of overall satisfaction between the two groups. Significantly more women receiving combined spinal-epidural analgesia had pruritus (P0.001) and requested additional epidural bolus doses of local anesthetic (P0.01). For all the women, dystocia necessitating cesarean section was significantly more likely when analgesia was administered with the fetal vertex at a negative station (odds ratio, 2.5; P0.001) or at less than $4 \mathrm{~cm}$ of cervical dilatation (odds ratio, 2.2; $\mathrm{P} 0.001$ ).

In the study conducted in 2002 by Dr Priya Gupta et al ${ }^{60}, 40$ patients of ASA 1 and 2 were divided into 2 groups randomly, group A patient received CSE using "needle through needle technique" and were given 2.5 $\mathrm{ml}$ of $0.5 \%$ bupivacaine in subarachnoid space. Group B patient received epidural block with catheter insitu with $15 \mathrm{ml}$ of $0.5 \%$ plain bupivacaine. In both groups subsequent dosage of $1.5-2 \mathrm{ml}$ per unblocked segment of $0.5 \%$ bupivacaine was given to raise the level of the block to T4-T5. Results showed that analgesia and motor blockade occurred early in CSE group, further duration of analgesia was shorter in CSE (81.75 $\pm 11.09 \mathrm{~min})$ as compared to epidural group $(120.75 \pm 7.56 \mathrm{~min})$. The total amount of bupivacaine required to attain the same target level was three times in epidural group $(\mathrm{p}<0.05)$. Hemodynamic changes were comparable in both groups. No neurological side effects were being observed.

In this particular study they used $18 \mathrm{G}$ Tuohy needle with air filled syringe and method to identify the space was loss of resistance technique. Long $27 \mathrm{G}$ spinal needle was introduced through the Tuohy needle till it penetrates dura mater. After injecting the subarachnoid dose, $20 \mathrm{G}$ epidural catheter was introduced, secured and its patency checked. After subarachnoid drug was fixed (15 min) $1.5-2 \mathrm{ml}$ per unblocked segment of $0.5 \%$ plain bupivacaine into epidural catheter was given and level extended to T4-T5 level.

In the study conducted by Dr. Dipasri Bhattacharya et al ${ }^{64}$ in 2007 sixty patients aged 65 to 80 years, ASA III were randomly allocated into two equal groups. Group A $(n=30)$ received sequential combined spinal epidural anaesthesia with $1 \mathrm{ml}(5 \mathrm{mg})$ of $0.5 \%$ hyperbaric bupivacaine with $20 \mathrm{mg}$ fentanyl through spinal route, and the expected incompleteness of spinal block was managed with small incremental dose of $0.5 \%$ isobaric bupivacaine through epidural catheter, 1.5 to $2 \mathrm{ml}$ for every unblocked segment to achieve T10 sensory level. Group B (n=30) received spinal anaesthesiawith $2 \mathrm{ml}(10 \mathrm{mg})$ of $0.5 \%$ hyperbaric bupivacaine and $20 \mathrm{mg}$ of fentanyl.

Both the groups showed rapid onset, excellent analgesia and good quality motor block. Group A showed a significantly less incidence of hypotension $(\mathrm{p}<0.01)$ along with the provision of prolonging analgesia as compared to group B.

In the review conducted by $\mathrm{Ng} \mathrm{K}$, Parsons J, Cyna AM, Middleton $\mathrm{P}^{67}$ in 2007, they have found out that there was no difference found between spinal and epidural techniques with regards to failure rate (RR 0.98, 95\% CI 0.23 to 4.24; four studies), need for additional intra operative analgesia (RR 0.88, 95\% CI 0.59 to 1.32 ; five studies), need for conversion to general anaesthesia intraoperatively, maternal satisfaction, need for postoperative pain relief and neonatal intervention. Women receiving spinal anaesthesia for caesarean section showed reduced time from start of the anesthetic to start of the operation (WMD7.91 minutes less (95\% CI 11.59 to -4.23 ; four studies), but increased need for treatment of hypotension RR 1.23 (95\% CI 1.00 to 1.51 ; six studies).

In a study done by Asha Tyagi et $\mathrm{al}^{63}$ in 2008 , 60patients were studied who received epidural volume extension (EVE) by $10 \mathrm{ml}$ normal saline and then according to level decrements were made by $1 \mathrm{ml}$, they concluded that minimum effective volume (MEV) of normal saline needed to raise the level of sensory block by two or more dermatome within 5 min of EVE was $7.4 \mathrm{ml}$. Epidural volume extension is emerging as a new concept, where normal saline injected through epidural catheter following subarachnoid block. Thereby increasing the level of sensory blockade.

In the study conducted by Amit G Bhagwat et al ${ }^{65}$ in 2008,the following results were found sixty healthy nulliparous parturients in spontaneous labour with singleton fetus were randomized in a prospectivedouble blinded manner to receive either CSE analgesia or epidural analgesia.

The epidural group $(n=30)$ received $10 \mathrm{ml}$ bolus of $0.0625 \%$ bupivacaine $+0.0002 \%$ fentanyl \& the CSE group $(n=30)$ received intrathecally 25 mcgfentanyl $+1.25 \mathrm{mg}$ bupivacaine. The rate of cervical dilatation was significantly greater in the CSE group as comparedto the epidural group $(3.5 \pm 0.752 \mathrm{~cm} / \mathrm{hr}$ vs. $2.0 \pm$ $1.122, P=0.000) \&$ the duration of active stage of first stageof labour was significantly shorter in-group CSE (117.5 $\pm 25.57 \mathrm{~min}$ vs. $192.5 \pm 12 \mathrm{~min}, P=0.000)$. 
Study - "Comparative Study Of Combined Spinal Epidural Versus Epidural .......

Luiz Eduardo Imbelloni et al $^{62}$ in 2009 performed a prospective randomized study comparing continuous spinal anaesthesia and combined spinal epidural block for major orthopedic surgery. They conducted the study over 240 patients. Where this patient posted for knee surgery, hip arthroplasty or femoral fracture treatment were randomly assigned to either CSA or CSE group blockades were performed in lateral position at L3 L4 spaces. Puncture success, technical difficulties, cardio circulatory changes and post dural puncture headache was recorded. At the end of surgery catheter was removed and CSF fluid leakage was evaluated. Results obtained from their study was seven patients were excluded (three CSA and four CSE). There was significantly lower incidence of paresthesia in the CSE group. The resultant sensory blockade level was significantly higher with CSE. Complete motor blockade occurred in 110 CSA patients and in 109 CSE patients. Hypotension was observed more in the patient with CSE anaesthesia. Post dural puncture headache was observed in two patients of both the groups. The upper limit of sensory block was higher when CSE technique was used (T11 and T10) ( $\mathrm{p}=0.001)$. The median level in patients receiving CSA was T12 (range: T7-T12) and it was T11 in patient receiving CSE (range: T5-T12). It has been also found out that after spinal injection of hyperbaric bupivacaine, epidural volume extension can be done to achieve a higher level of sensory blockade.

Dr.Michele Cacciapaglia et al $^{96}$, in 2012 performed a study in Italy, on 50 patients undergoing urologic surgery and concluded that combined sequential spinal epidural anaesthesia allowed a pain free procedure. The pinprick test score was $1.2 \pm 0.7$ at the T7 dermatome level. CI, mean BP and HR were stable during the entire procedure. The Aldrete Score was $9.84 \pm 0.4$.

Inclusion criteria were age $\geq 18$ years and surgery scheduled to last $\leq 2$ hours. Patients with a history of hypertension, congestive heart failure, any active medication for cardiovascular disease or any other absolute or relative contraindication to spinal anesthesia were excluded from the study. Patients undergoing urologic procedures received CSE with $4 \mathrm{ml}$ of Levobupivacaine $0.075 \%$ intrathecally, followed by $10 \mathrm{ml}$ of Levobupivacaine $1.5 \%$ epidurally. Sensory block spread was assessed by a pin prick test. Cardiac index (CI), blood pressure (BP), heart rate (HR) and arterial saturation of $\mathrm{O} 2(\mathrm{SpO} 2)$ were continuously monitored and recorded. Before discharge, patient's functional status was assessed by the Aldrete Score.

Combined sequential spinal epidural anaesthesia performed with low doses of local anesthetics allowed a good sensory block and was associated with good hemodynamic conditions and recovery score.

Dr Nagaraju talikota et al ${ }^{61}$, in 2015 performed a randomized controlled trial comparing the efficacy and safety of sequential combined spinal epidural with spinal block for lower abdominal surgeries. They randomly allocated 50 patients to either groups. Group A patient received spinal anaesthesia by $24 \mathrm{G}$ needle at L3 L4 interspace and $3 \mathrm{cc}$ of heavy bupivacaine is injected. In the second group 18 G Tuohy needle was used and loss of resistance and four quadrant aspiration was used to identify the epidural space. Results obtained were, time taken for onset of anaesthesia was shorter in SA group compared to CSEA group. Time taken for onset of analgesia was $5.48 \mathrm{~min}$ in SA group compared to $7.40 \mathrm{~min}$ in CSEA group with a mean difference of 1.92 min (95\% CI: 0.78-3.05, p-value 0.001). The duration of analgesia was 115.6 min in group A compared to 124.5 in group B, with a mean difference of $8.92 \min (95 \% \mathrm{CI}: 0.87-18.71$, p-value 0.07$)$.

The proportion of subjects who achieved the excellent quality of surgical analgesia was $92 \%$ in group A compared to $88 \%$ in group B. The remaining $8 \%$ and $12 \%$ of subjects the quality of the anaesthesia was good. None of the patient had fair or poor quality of analgesia. All patients achieved good level of muscle relaxation.

\section{Bupivacaine}

It was synthesized by O.F Ekenstan in 1957. It is the first long acting amino-amide local anesthetic agent. It was introduced in clinical practice by Widman in 1963. It is chemically designated as 2piperidinecarboxamide, 1-Butyl-N-(2, 6- dimethyl phenyl)-, monohydrochloride, monohydrate and has the following structure--

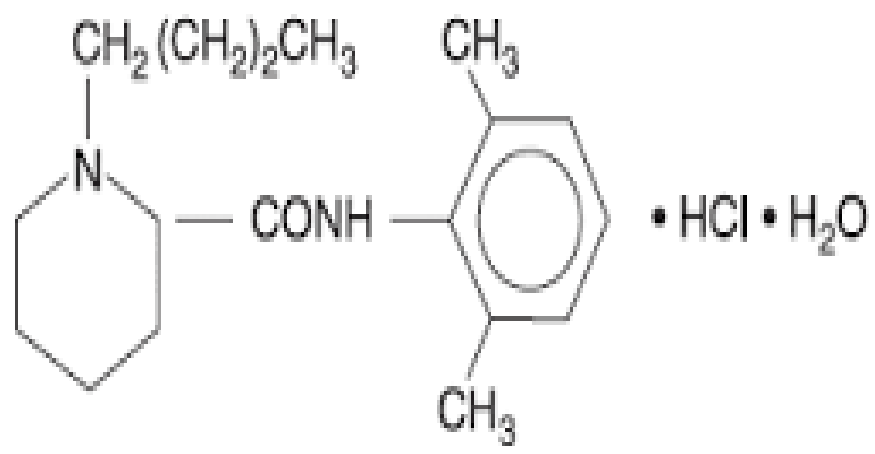

Fig 8: Chemical formula Bupivacaine. 


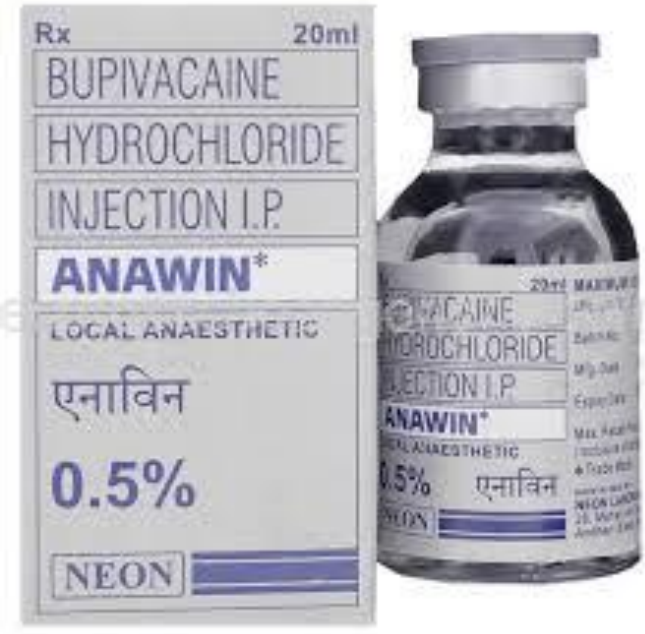

Fig 9: Commercial form of Bupivacaine

\section{Mechanism Of Action}

Bupivacaine reversibly interferes with the entry of sodium into the nerve cell membranes, leading to decreased membrane permeability to sodium and raises the threshold for electricalexcitability ${ }^{68}$. It blocks the generation and the conduction of nerve impulses, presumably byincreasing the threshold for electrical excitation in the nerve, by slowing the propagation of thenerve impulse, and by reducing the rate of rise of the action potential. Binding affinities of localanesthetics to sodium channels are stereo specific and depend on the conformational state of thesodium channel. ${ }^{69}$ Sodium channels exist in activated (open), inactivated (closed) and resting(closed) states during various phases of the action potential.

Bupivacaine selectively binds to sodium channels in the inactivated closed state, thereby stabilizing these channels and preventing their change to rested closed and activated open states in response to nerve stimulus. It binds to specific sites located on the inner position of the sodium channels and obstructs the external openings and maintains them in the inactivated closed state, which is not permeable to sodium, so that the conduction of nerve impulses does not occur. On repeated application of depolarization, partially depressed sodium ion current (tonic inhibition) is further reduced leading to phasic inhibition called use dependent block. The sole use of local anesthetic is less common than the use of local anesthetic-opioid combination because of a significant failure rate (regression of sensory block and inadequate analgesia) and relatively high incidence of hypotension. In general, the progression of Anaesthesia is related to the diameter, myelinationand conduction velocity of affected nerve fibers. Clinically, the order of loss of nerve function is as follows: (1) pain, (2) temperature, (3) touch, (4) proprioception, and (5) skeletal muscle tone.

\section{Physiochemical Properties}

Bupivacaine Hydrochloride is 2-Piperidinecarboxamide, 1-Butyl-N-(2,6-dimethylphenyl)-, monohydrochloride, monohydrate, a white crystalline powder that is freely soluble in 95 percent ethanol, soluble in water, and slightly soluble in chloroform or acetone. The pKa of bupivacaine is 8.1. However, bupivacaine possesses a greater degree of lipid solubility and is protein bound to a greater extent than lidocaine. It is $95 \%$ protein bound. It is a chiral drug having a left(S) or right (R) configuration. It is available for clinical use as racemic mixtures of the enantiomers. It is 4 times more potent than lidocaine. The dural permeability and the movement of local anesthetic through the sodium channel of the nerve membrane is claimed to be more dependent on the molecular weight. The molecular weight of bupivacaine is 288: most other local anesthetics are of smaller molecular weights. High lipid solubility promotes diffusion through membranes, thereby speeding the onset of action and also increasing the potency and duration of effect. Higher the aqueous lipid solubility coefficient (343 for bupivacaine), more rapid is the entry into the lipid membrane and longer is the duration of action. $^{70}$

\section{Differential Conduction Block}

With low concentrations of local anesthetic, selective blockade of pre-ganglionic sympathetic nervous system B fibers occur. Slightly higher concentrations interrupt conduction in small Cfibers and small and medium sized A fiber with loss of pain and temperature sensation. This is due to varying existing critical lengths of nerve block of different types and fibers and also measures the density of sodium channels that appears to decrease as fiber diameter decreases. ${ }^{70}$ 


\section{Pharmacokineticsabsorption}

The rate of systemic absorption of local anesthetics is dependent upon the total dose and concentration of drug administered, the route of administration, the vascularity of the administration site, and the presence or absence of epinephrine in the anesthetic solution. A dilute concentration of epinephrine $(1: 200,000 \mathrm{or} 5 \mathrm{mg} / \mathrm{mL})$ usually reduces the rate of absorption and peak plasma concentration of bupivacaine, permitting the use of moderately larger total doses and sometimes prolonging the duration of action. The onset of action with bupivacaine is rapid and Anaesthesia is long-lasting. The duration ofAnaesthesia is significantly longer with bupivacaine than with any other commonly used local anesthetic. It has also been noted that there is a period of analgesia that persists after the return of sensation, during which time the need for potent analgesics is reduced.

\section{Distribution}

Local anesthetics are bound to plasma proteins in varying degrees. Generally, the lower the plasma concentration of drug, the higher the percentage of drug bound to plasma proteins. Local anesthetics appear to cross the placenta by passive diffusion. The rate and degree of diffusion is governed by: (1) the degree of plasma protein binding, (2) the degree of ionization, and (3) the degree of lipid solubility. Fetal/maternal ratios of local anesthetics appear to be inversely related to the degree of plasma protein binding, because only the free, unbound drug is available for placental transfer. Bupivacaine, with a high protein binding capacity $(95 \%)$, has a low fetal/maternal ratio (0.2-0.4). First pass pulmonary extraction is dose dependent. ${ }^{71}$ The extent of placental transfer is also determined by the degree of ionization and lipid solubility of the drug. Lipid soluble, non-ionized drugs readily enter the fetal blood from the maternal circulation.

Depending upon the route of administration, local anesthetics are distributed to some extent to all body tissues, with high concentrations found in highly perfused organs such as the liver, lungs, heart and brain.

Pharmacokinetic studies on the plasma profile of bupivacaine after direct intravenous injection suggest a three-compartment open model. The first compartment is represented by the rapid intravascular distribution of the drug. The second compartment represents the equilibration of the drug throughout the highly perfused organs such as the brain, myocardium, lungs, kidneys, and liver. The third compartment represents an equilibration of the drug with poorly perfused tissues, such as muscle and fat. The elimination of drug from tissue depends largely upon the ability of binding sites in the circulation to carry it to the liver where it is metabolized. After injection of bupivacaine for caudal, epidural or peripheral nerve block in man, peak levels of bupivacaine in the blood are reached in 30 to 45 minutes, followed by a decline to insignificant levels during the next 3 to 6 hours.

Various pharmacokinetic parameters of the local anesthetics can be significantly altered by the presence of hepatic or renal disease, addition of epinephrine, factors affecting urinary $\mathrm{pH}$, renal blood flow, the route of drug administration, and the age of the patient. The half-life of bupivacaine in adults is 2.7 hours and in neonates 8.1 hours. $^{70}$

In clinical studies, elderly patients reached the maximal spread of analgesia and maximal motor blockade more rapidly than younger patients. Elderly patients also exhibited higher peak plasma concentrations following administration of this product. The total plasma clearance was decreased in these patients.

\section{Metabolism}

Amide-type local anesthetics such as bupivacaine are metabolized primarily in the liver via conjugation with glucuronic acid. Patients with hepatic disease, especially those with severehepatic disease, may be more susceptible to the potential toxicities of the amide-type localanesthetics.

The major metabolite of bupivacaine is $\mathrm{N}$-desbutyl bupivacaine. ${ }^{72}$ The clearance rate is 0.47 liters $/ \mathrm{min}$.

\section{Excretion}

The kidney is the main excretory organ for most local anesthetics (bupivacaine) and their metabolites. Urinary excretion is affected by renal perfusion and factors affecting urinary ph.Only 5\% of bupivacaine is excreted unchanged in the urine. The elimination half-life is 210 minutes. In infants and elderly, the half-life is prolonged. When administered in recommended doses and concentrations, bupivacaine does not ordinarilyproduce irritation or tissue damage and does not cause methemoglobinemia.

\section{Pharmacodynamics}

Systemic absorption of local anesthetics (bupivacaine) can produce effects on the central nervous and cardiovascular systems. At blood concentrations achieved with therapeutic doses, changes in cardiac conduction, excitability, refractoriness, contractility, and peripheral vascular resistance have been reported. Toxic blood concentrations depress cardiac conduction and excitability, which may lead to atrioventricular block, ventricular arrhythmias and to cardiac arrest, sometimes resulting in fatalities. In addition, myocardial contractility is depressed and peripheralvasodilation occurs, leading to decreased cardiac output and arterial 
Study - “Comparative Study Of Combined Spinal Epidural Versus Epidural .......

blood pressure. Following systemic absorption, local anesthetics (bupivacaine) can produce central nervous system stimulation, depression or both. Apparent central stimulation is usually manifested as restlessness, tremors and shivering, progressing to convulsions, followed by depression and coma, progressing ultimately to respiratory arrest. However, the local anesthetics have a primary depressant effect on the medulla and on higher centers. The depressed stage may occur without a prior excited stage. ${ }^{70}$

\section{Dosage And Administration}

The rapid injection of a large volume of bupivacaine solution should be avoided and fractional(incremental) doses should always be used. The smallest dose and concentration required to produce the desired result should be administered.

The dose of any local anesthetic administered varies with the anesthetic procedure, the area to be anesthetized, the vascularity of the tissues, the number of neuronal segments to be blocked, the depth of anaesthesia and degree of muscle relaxation required, the duration of anaesthesiadesired, individual tolerance, and the physical condition of the patient. Patients in poor general condition due to aging or other compromising factors such as partial or complete heart conduction block, advanced liver disease or severe renal dysfunction require special attention although regional anaesthesia is frequently indicated in these patients. To reduce the risk of potentially serious adverse reactions, attempts should be made to optimize the patient's condition before major blocks are performed, and the dosage should be adjusted accordingly.

In recommended doses, bupivacaine hydrochloride produces complete sensory block, but the effect on motor function differs among the three concentrations.

$\mathbf{0 . 2 5 \%}$ - when used for caudal, epidural, or peripheral nerve block, produces incomplete motor block. Should be used for operations in which muscle relaxation is not important, or when another means of providing muscle relaxation is used concurrently. Onset of action may be slower than with the $0.5 \%$ or $0.75 \%$ solutions.

$\mathbf{0 . 5 \%}$ - provides motor blockade for caudal, epidural, or nerve block, but muscle relaxation maybe inadequate for operations in which complete muscle relaxation is essential.

$\mathbf{0 . 7 5 \%}$ - produces complete motor block. Most useful for epidural block in abdominal operations requiring complete muscle relaxation, and for retro bulbar anaesthesia. Not for obstetricalAnaesthesia.

The duration of anaesthesia with bupivacaine is such that for most indications, a single dose is sufficient.

Maximum dosage limit must be individualized in each case after evaluating the size and physical status of the patient, as well as the usual rate of systemic absorption from a particular injection site. Most experience to date is with single doses of bupivacaine up to $225 \mathrm{mg}$ with epinephrine 1:200,000 and $175 \mathrm{mg}$ without epinephrine; more or less drug may be used depending on individualization of each case.

These doses may be repeated up to once every three hours. In clinical studies to date, total daily doses up to $400 \mathrm{mg}$ have been reported. Until further experience is gained, this dose should not be exceeded in 24 hours. The duration of anesthetic effect may be prolonged by the addition of epinephrine.

These dosages should be reduced for young, elderly or debilitated patients. Until further experience is gained bupivacaine is not recommended for children younger than 12 years.

Bupivacaine is contraindicated for obstetrical paracervical blocks, and is not recommended for intravenous regional anaesthesia (Bier Block).

\section{Use in Epidural Anaesthesia}

During epidural administration of bupivacaine, $0.5 \%$ and $0.75 \%$ solutions should be administered in incremental doses of $3 \mathrm{~mL}$ to $5 \mathrm{~mL}$ with sufficient time between doses to detect toxic manifestations of unintentional intravascular or intrathecal injection. In obstetrics, only the $0.5 \%$ and $0.25 \%$ concentrations should be used; incremental doses of $3 \mathrm{~mL}$ to $5 \mathrm{~mL}$ of the $0.5 \%$ solution not exceeding $50 \mathrm{mg}$ to $100 \mathrm{mg}$ at any dosing interval are recommended. Repeat doses should be preceded by a test dose containing epinephrine if not contraindicated. Use only the single dose ampoules and single dose vials for caudal or epidural Anaesthesia; the multiple dose vials contain a preservative and therefore should not be used for these procedures

\section{Factors influencing anaesthetic activity Addition of vasoconstrictor:}

The duration of action of bupivacaine is proportional to the time the drug is in contact with the nerve fibers. The addition of vasoconstrictor like epinephrine will prolong the duration of action of drug. However, the effect of prolonging the duration of action by adding epinephrine is less than that observed withlidocaine which is attributed to its high lipid solubility.

\section{Dosage of the drug:}

Increase in dose of bupivacaine either by larger volume or more concentrated solution results in more profound depth, prolonged duration and faster onset of block.

\begin{tabular}{|c|c|}
\hline DOI: $10.9790 / 0853-16030596128$ & www.iosrjournals.org \\
\hline
\end{tabular}




\section{Site of injection:}

Rapid onset and shorter duration occur with intrathecal or subcutaneous infiltration of bupivacaine.

\section{Carbonation and ph adjustment:}

An increase in the $\mathrm{pH}$ of the drug increases the amount of drug in the unionized for resulting in faster onset of conduction blockade. Carbon dioxide raises the threshold for impulse firing by changing the extent of channel inactivation at rest.

\section{Liposomal local anaesthetics:}

Large unilamellar vesicles that exhibit a Ph.gradient can efficiently encapsulate bupivacaine and subsequently provide a sustained releasesystem that greatly increases the duration of neural blockade when compared with plain localanesthetic solutions ${ }^{73}$.

\section{Side effects}

1. Allergic reactions

2. Systemic toxicity

\section{Allergic reactions:}

They are less than $1 \%$ and are immunologically mediated ${ }^{74}$. Theoccurrence of rash, utricaria and laryngeal edema with or without hypotension andbronchospasm during intradermal testing is highly suggestive of allergic reactions.

\section{Systemic toxicity:}

Bupivacaine toxicity occurs due to excess plasma concentration of the drug. The magnitude of systemic absorption depends on the dose administered into the tissue, vascularity at the injection site, presence of epinephrine in the solution. CNS manifestations occur with plasma concentrations of $4.5-5.5 \mathrm{mcg} / \mathrm{ml}^{75}$. The features are numbness of tongue and circumoral tissues, restlessness, vertigo, tinnitus, and difficulty in focusing, slurred speech, skeletal muscle twitching of face and extremities and convulsions. The treatment comprises oxygenation, ventilation and intravenous midazolam.

In the 1980's reports indicated that bupivacaine possessed a relatively high potency for cardiotoxicity. Accidental IV injection of bupivacaine results in precipitous hypotension, cardiacdysrhythmias and atrioventricular heart block $^{76}$. It is found that due to rapid saturation of the protein binding sites, significant mass of unbound drug is available for diffusion into the conducting system of heart. Cardio toxicity occurs at a plasma concentration of $8-10 \mathrm{mcg} / \mathrm{ml}^{77}$.

The threshold for cardiac toxicity produced by bupivacaine may be decreased in patients onantidysrhythmic drugs and medications which depress impulse propagation (beta blockers, digitalis and calcium channel blockers $)^{78}$. In the presence of propanolol, cardio toxic effects occur at $2-3 \mathrm{mcg} / \mathrm{ml} \mathrm{of} \mathrm{plasma}$ concentration. Epinephrine and Phenylephrine also increasesbupivacaine toxicity.

Dissociation of highly lipid soluble bupivacaine from sodium channel receptor site is slowcausing persistent depressant effect on Vmax and cardio toxicity ${ }^{79}$. Patients with cardiac depression or cardiac arrest due to bupivacaine toxicity will be difficult to resuscitate. Renantiomer of bupivacaine is more toxic than the $S$ enantiomer. Tachycardia can enhancefrequency dependent blockade of cardiac channels by bupivacaine leading to cardiac toxicity ${ }^{80}$.

Bretylium $20 \mathrm{mg} / \mathrm{kg}$ IV reverses bupivacaine induced cardiac depression and increase the threshold for ventricular tachycardia ${ }^{81}$. On intravascular infusion of encapsulated bupivacaine inmultilamellar liposome, the nervous and cardiac toxicity of bupivacaine was found to bereduced ${ }^{82}$. Intralipid or commonly available IV lipid emulsion can be effective in treating severe cardiac toxicity secondary to local anesthetic over dosage. Human cases have been reported with successful use of Intralipid in the treatment of cardiac toxicity ${ }^{83,84}$.

\section{Neurotoxicity}

Spinal anaesthesia with $0.5 \%$ bupivacaine is associated with a lower incidence of transientradicular irritation compared to lidocaine ${ }^{85}$.

Uses

Bupivacaine is used for local infiltration, epidural anaesthesia and analgesia, spinal anaesthesiaand all peripheral nerve blocks.

\section{Recent Advances}

Apart from sodium channel blockade, non-sodium channel action also plays an important beneficial role by local anesthetics in subtle modulation on neutrophil function. They selectively inhibit priming without affecting activation of neutrophils and prevent hyper sensitization causing tissue damage. This effect occurs at much lower concentration than those required for sodium channel blockade. This is mediated by local anaesthetic interactions with $\mathrm{G}$ proteinsignaling ${ }^{86}$. 


\section{Contraindications}

Presence of hypersensitivity to local anesthetics of the amide type or other components ofbupivacaine solutions. Other conditions are presence of inflammation and or sepsis near the proposed site of injection, severe shock, heart block and for intravenous regional anaesthesia(IVRA).

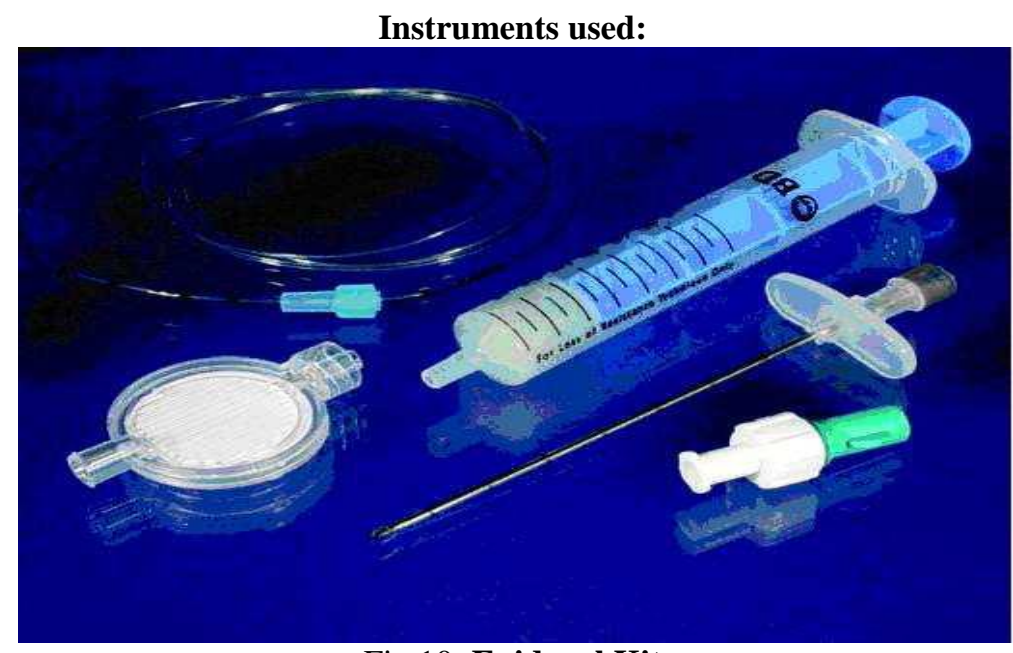

Fig 10: Epidural Kit

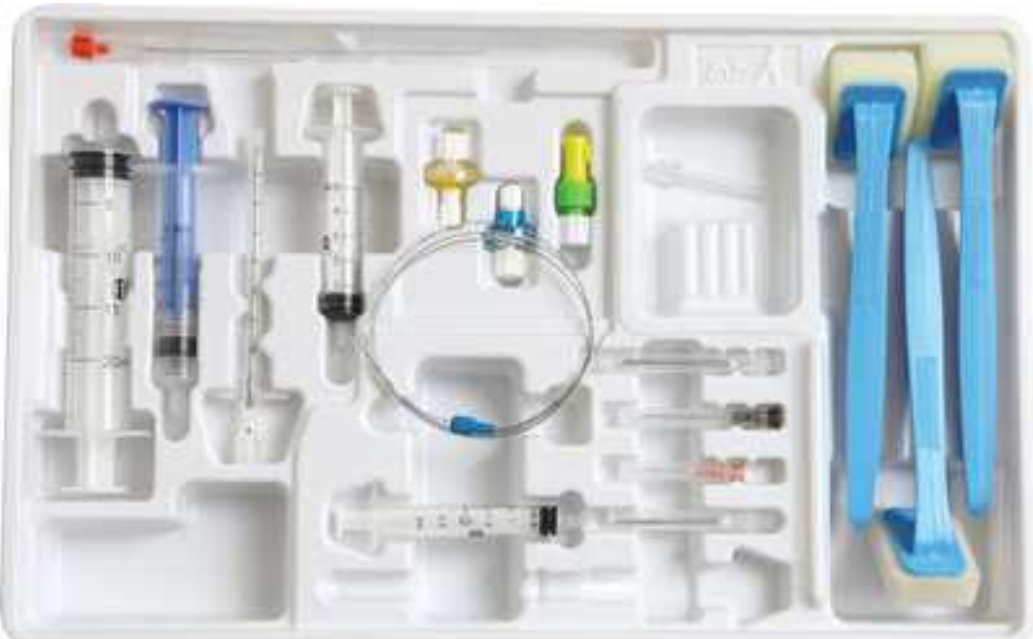

Fig 11: Combined Spinal Epidural Kit (Sterile sponges, Loss of resistance syringe, epidural microcatheter, catheter ports, local anaesthetic syringe)

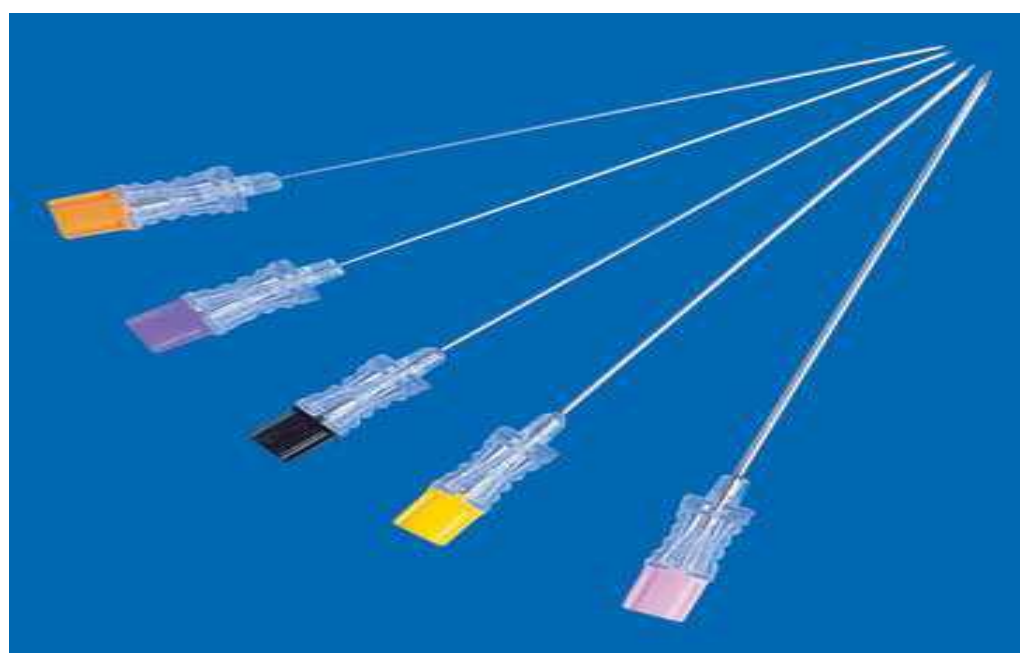


Grey -27 G, Brown - 26 G, Orange - 25 G, Blue - 23 G

\section{The Physiology of Pain:}

Pain is a dynamic phenomenon. From the periphery to the brain, the nociceptivesignal will be modulated at all levels of the central nervous system(CNS).The current science regarding concepts of pain mechanismsalso takes into account genetic and environmental factors that will influencethe development of persistent pain.Multiple endogenous excitatory and inhibitory mechanisms have beenidentified ${ }^{87}$ for the causation of pain.

\section{From nociception to pain:}

A good way to understand the physiology of pain is to follow the nociceptivesignal pathways from the periphery to the brain, with emphasis on the integration and modulation of the nociceptive signal at different steps inthe CNS.

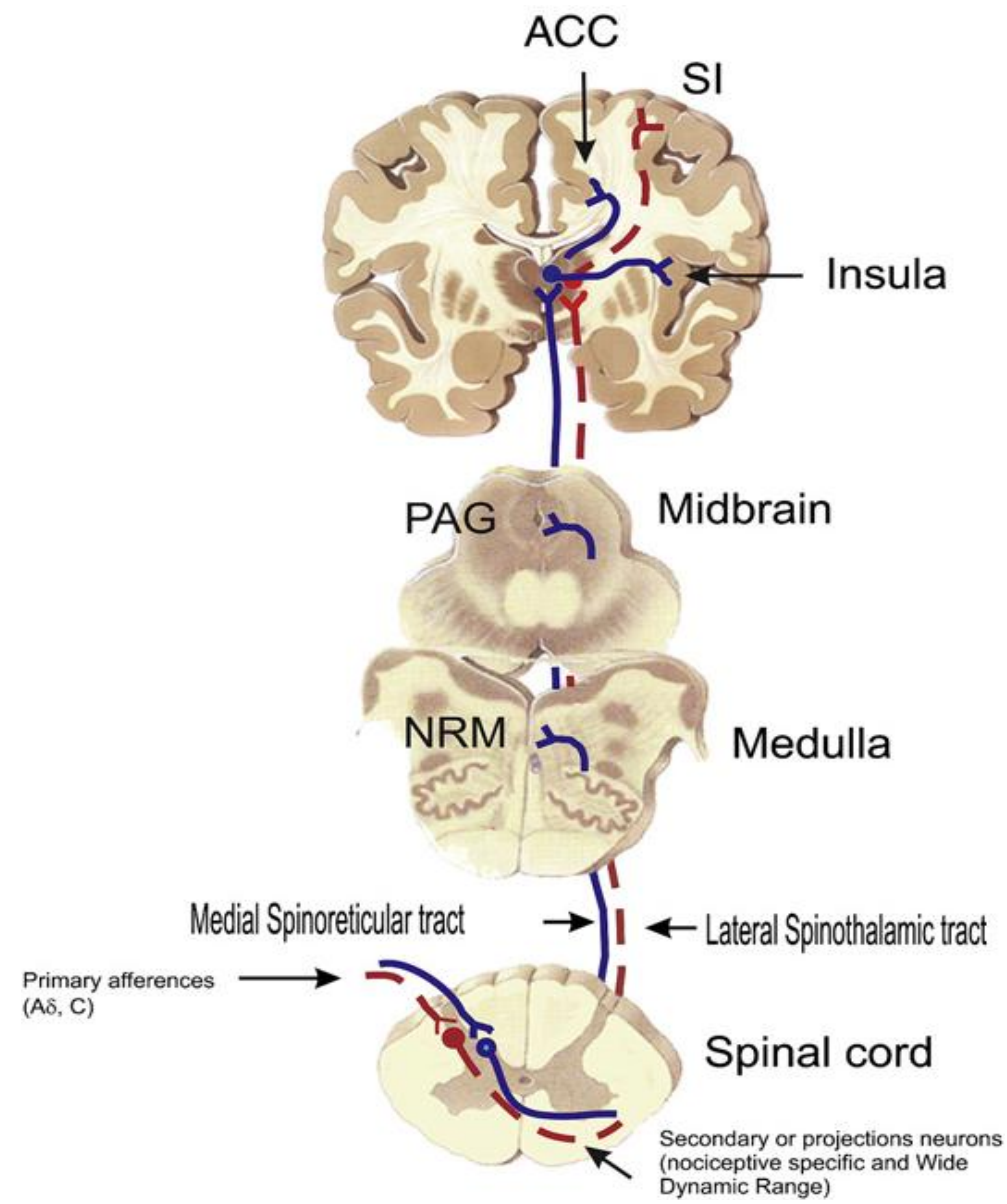

Fig 13: Nociceptivesignal pathways

nociceptive pathways from the periphery will conduct to the brain after two synapticrelays. The Ad and $\mathrm{C}$-fibers will make their first synapse with the projection neurons in thedorsal horn of the spinal cord. The secondary neurons will decussate immediately in the cordand conduct to the thalamic nuclei, where they will make the second synaptic contact.

The thirdneurons will finally project to the somatosensory cortices for the sensory-discriminative componentof pain, and to limbic structures (anterior cingulated cortex and insula) for the motivationalcomponent of pain.SI,SII, somatosensory cortices;

\section{The periphery: The nociceptors}

An injury that causes a potential risk for the organism will activate free nerve endings that respond to nociceptive stimulation. Most of thesefibers are polymodal and will respond to different modalities, including mechanical,thermal, and chemical stimulation ${ }^{88}$. 
Table 2: Types of nerve fibers carrying pain.

\begin{tabular}{|l|l|l|l|}
\hline & \multicolumn{1}{|c|}{$\mathbf{A} \boldsymbol{\beta}$} & \multicolumn{1}{c|}{ A $\boldsymbol{C}$} & \multicolumn{1}{c|}{$\mathbf{C}$} \\
\hline Diameter & $\begin{array}{l}6 \text { to } 12 \mu \\
\text { myelinated }\end{array}$ & $\begin{array}{l}1 \text { à } 5 \mu \\
\text { myelinated }\end{array}$ & $\begin{array}{l}0,2 \text { à } 1,5 \mu \\
\text { unmyelinated }\end{array}$ \\
\hline Conduction & 35 to $75 \mathrm{M} / \mathrm{s}$ & 35 to $75 \mathrm{M} / \mathrm{s}$ & 35 to $75 \mathrm{M} / \mathrm{s}$ \\
\hline Role & $\begin{array}{l}\text { Light touch, } \\
\text { proprioception }\end{array}$ & $\begin{array}{l}\text { Temperature, } \\
\text { Nociception } \\
\text { (mechanical, thermal) }\end{array}$ & $\begin{array}{l}\text { Nociception } \\
\text { (mechanical, thermal } \\
\text { and chemical) }\end{array}$ \\
\hline
\end{tabular}

A nociceptive stimulation will initiate a cascade of events. Pronociceptiveinflammatory molecules will be released into the periphery and will produceperipheral hyperalgesia. These pronociceptive inflammatory moleculesoriginate in various blood cells (mastocytes, polymorphonuclear cells, andplatelets) and include bradykinins, prostaglandins, histamine, serotonin,adenosine triphosphate, and also from immune cells which produce interleukins,interferon, and tumor necrosis factors ${ }^{89,90,91,92}$. Substance $\mathrm{P}$ and calcitoningene related protein (CGRP), which act as neurotransmitters in theCNS, are also released into the periphery and act as proinflammatory factorsin the periphery, favoring neurogenic inflammation ${ }^{89}$.

\section{First and second pain:}

The conduction velocity differences between the Ad and $\mathrm{C}$ fibers can beappreciated when isolating the sensation of first and second pain .Following a brief nociceptive stimulation, the Ad fibers will rapidly transmita brief and acute pinprick-like sensation, perceived to be precisely located atthe point of stimulation. It is this precision and fast conduction that will resultin the nociceptive withdrawal reflex. Following this activity, $\mathrm{C}$ fibers willtransmit their information with a relatively long delay (100 milliseconds toa second, depending on the stimulus location). This second sensory input resultsin a more diffuse deep pain sensation.

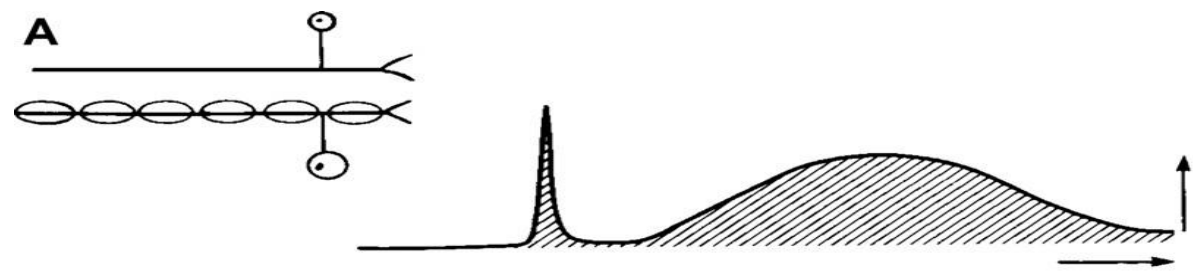

B

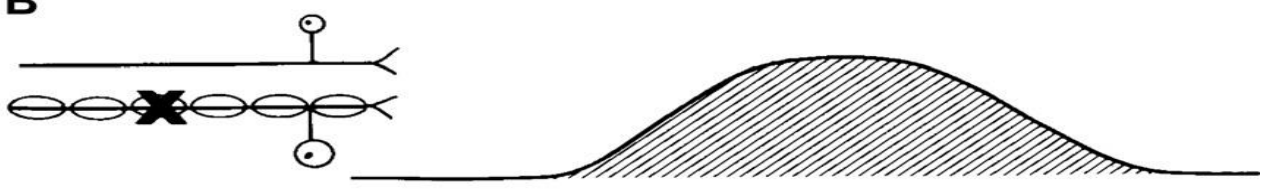

C

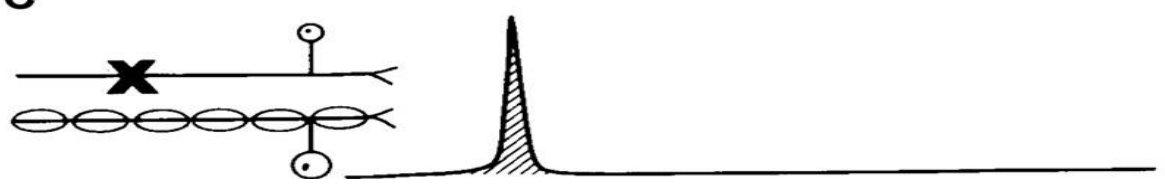

Fig. 14.Conduction among the various nerve fibres

Because of the differences in conduction velocity between the relatively rapid and slow C-fibers, a nociceptive stimulation will induce a first pain having the characteristics of a localizedand sharp pinprick sensation related to the fast action of the fibers, and a second slower andmore diffuse burning-like perception related to the slower activity of the C-fibers (A). Usinga blood pressure cuff, one can temporarily block the activity of the fibers with largest diameter,including the Ad fibers (B). This allows the activity of C-fibers to be isolated and independentlystudied ${ }^{93}$. 
A nociceptive stimulus will only conduct the C-fiber activity, perceived as a diffuseburning sensation independently of the stimulation type (B). If the activity of the small C-fibersis blocked by using capsaicin, only the sharp pinprick perception will persist (C).

\section{Method of transmission among the nerve fibres in the physiology of various types of pain:}

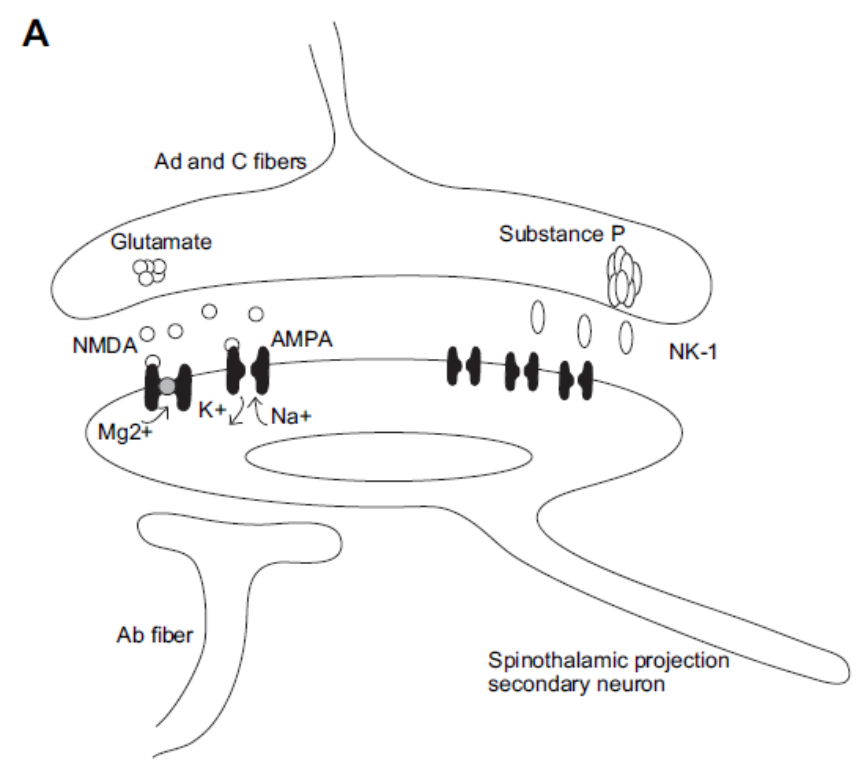

Fig 15:Transmission among the nerve fibres in the physiology of pain. (A)

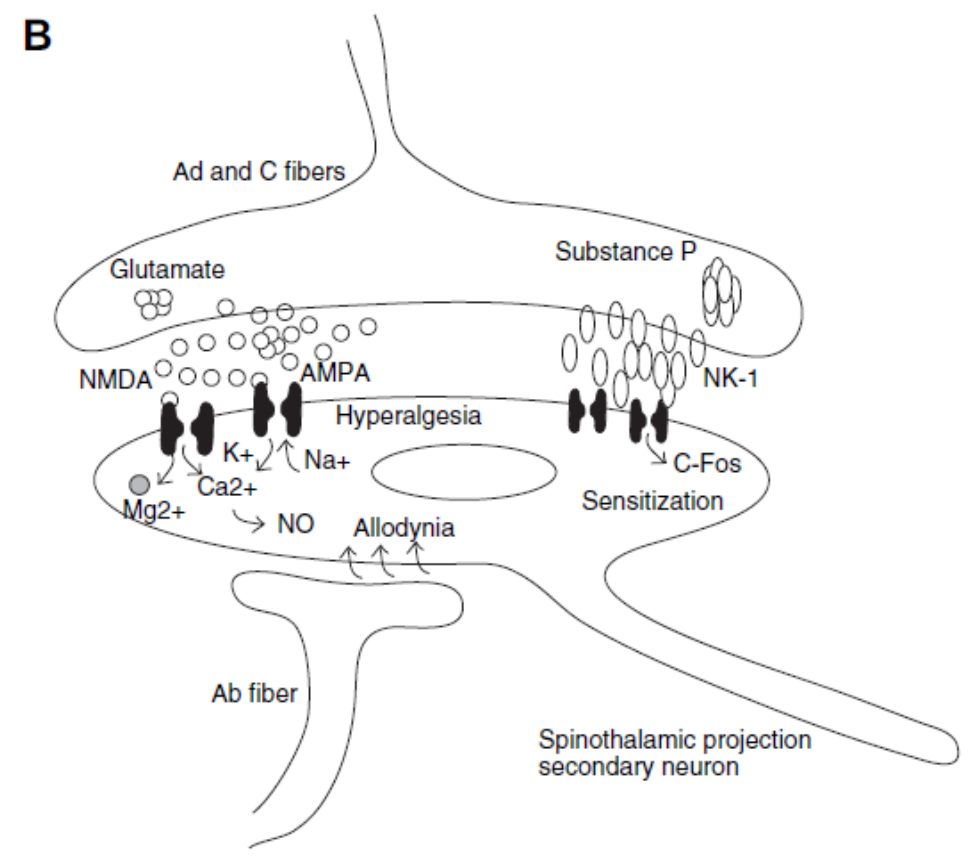

Fig 16: Transmission among the nerve fibres in the physiology of pain. (B)

Spinal sensitization occurs when the secondary neurons of the spinal cord change theirdischarge frequency following a sustained recruitment from the primary nociceptive afferences.In this schematic representation, one can see that an acute discharge from the nociceptive primaryafferences (C-fibers) will induce the release of peptide (substance P, CGRP) and glutamatethat will produce the recruitment of the NK1 and AMPA receptors (A). A sustained discharge(B) will recruit the NMDA receptors and produce a sensitization of the secondary neurons thatwill now discharge at a higher frequency when recruited by nociceptive (hyperalgesia) and non-nociceptive stimulation (allodynia). This phenomenon is generally transitory, but may persistover a long time and participate in pain chronicization. AMPA, alpha-amino-3-hydroxy-5-methyl-4- 
isoxazolepropionic acid; Ca, calcium; K, potassium; Mg, magnesium; Na, sodium;NK1, neurokinin; NMDA, Nmethyl-D-aspartate.

\section{Brain and pain:}

Pain can only be experienced when nociceptive afferent reaches the cortex. It is for this reason that the term nociception is used to describe the signal following a lesion, whereas pain is a complex perception requiring CNS activity.A complex network of cortical structures is activated during pain perception. Similar to the thalamic nuclei, the cortex can be represented in a simplifiedway by subdivision into structures involved in either the sensory or theaffective components of pain. Brain imaging has demonstrated four corticalstructures important for the perception of pain ${ }^{94,95}$. There are the somatosensorycortex (SI) in the postcentral circumvolution of the parietallobe, the secondary somatosensory cortex (SII) in the parietal operculum,the ACC above the corpus callosum circumvolution, and the insular cortex(IC) under the temporal and frontal lobes at the level of the Sylvian fissure.

The first two structures (SI and SII) are mainly involved in the sensory discriminativeaspect of pain, while the ACC and IC are associated with theaffective component of pain ${ }^{93}$.

\section{Endogenous pain modulation mechanisms:}

As pain is a dynamic phenomenon, the nociceptive signal will be modulatedat multiple levels of the CNS before pain is fully perceived. Because ofthe dynamic andplastic characteristics of the nervous system, pain perception, especially in a chronic pain condition, will change over time, dependenton different factors. Pain perception is the final outcome of complexmechanisms that modulate the nociceptive afferent signal. The modulationof the nociceptive signal starts at the periphery and involves several CNSstructures, including excitatory and inhibitory mechanisms from the brainstem, the autonomic nervous system, and the cortical structures responsible for the emotional and cognitive aspect of pain perception.

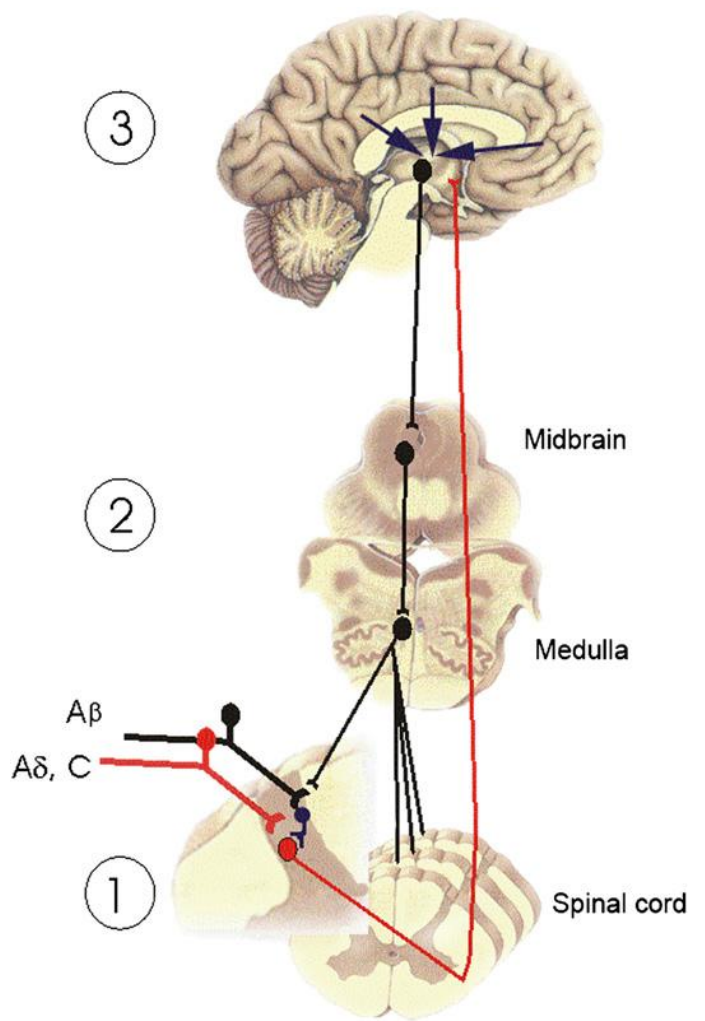

Fig. 17. Endogenous pain modulation.

This schematic representation of the main three levels of endogenous pain modulation presents: (1) the spinal, (2) descending from the brainstem, and (3)higher center inhibitory mechanisms. As described in this article, better understanding thesemechanisms help in developing a mechanistic approach for the treatment of some chronicpain conditions that are related to a deficit of these mechanisms. Serotonin and noradrenalinare two neurotransmitters implicated in diffuse noxious pain inhibitory mechanism (DNIC).However, other neurotransmitters, such as dopamine, are also implicated. The spinal interneuronis proposed to be enkephalinergic, but other inhibitory interneurons, such as gamma-aminobutyricacid (GABA), are also 
implicated. The secondary projection neurons have NMDAreceptors that are implicated in the persistency of certain neurogenic chronic pain conditions.The PAG in the mesencephalon and theNRM are two regions implicated in descendinginhibition.

\section{Risk factors for developing chronic pain:}

Understanding factors other than the primary disease process that are involved in the development and maintenance of pain will help toward preventionof a chronic pain state. Three factors have been proposed to play a rolein the chronicity of pain: personal predisposition, environmental factors, and psychologic factors. Paying attention to these elements will facilitatethe management of patients with chronic pain ${ }^{93}$.

This is a randomized controlled clinical study over a period of 11/2 years from October 2014 to April 2016 in the Department of Anesthesiology on Patients coming to SVMCHRC for surgical procedures lasting upto3 hours.

\section{Sample size:}

Sample size is calculated based on a published clinical trial done comparing the CSE and epidural block alone. The calculated sample size is 30 in each group with $90 \%$ power, $95 \%$ confidence interval and at 0.05 level of significance.

\section{Inclusion Criteria}

- ASA I \& II

- Age 20 to 60 years of both Sex

- Undergoing lower limb and lower abdominal surgeries up to 3 hours.

\section{Exclusion Criteria}

- >ASA III

- Infection at the site of injection

- Spinal abnormalities

- Neurological disorders \&

- Coagulation disorders

- Patients converted to general anesthesia

After Institutional Ethical \& Scientific Committee Board approval and informed written consent,60 patients were enrolled in the trial. Patients were randomized into one of the two groups:Group $C(n=30)$ for CSE and Group E $(n=30)$ for Epidural block.A thorough pre-anesthetic assessment was done prior to the day of surgery which included past history of chronic illness and medication, drug therapy (especially corticosteroids, anti-hypertensive, anti-coagulant, anti-diabetic, anticonvulsant medications), drug sensitivity and past anesthetic experience along with routine investigations.Informed and written consent was obtained after explaining the procedure to the patients.

Patients were premedicated with

○ tab ranitidine $150 \mathrm{mg}$,

- tab metoclopramide $4 \mathrm{mg} \&$

○ tab alprazolam $0.25 \mathrm{mg}$.

- Preloaded with Ringer lactate $10 \mathrm{ml} / \mathrm{Kg}$ for 20 minutes

- Combined Spinal Epidural Block was given to group C patients. Patients were given subarachnoid block with $2.5 \mathrm{ml}$ of $0.5 \%$ heavy bupivacaine initially following which epidural Catheter was placed in situ at a separate intervertebral space. The analgesic level obtained will be checked and extended by administering $0.5 \%$ plain bupivacaine $1.5-2 \mathrm{ml} /$ unblocked segment required for surgical anesthesia.

- Only Epidural block was given to group E patients with an in situ epidural catheter.

- Following parameters were noted

- Time to Onset of sensory block,

- Time to Onset of motor block

- quality of surgical analgesia by pinprick method,

- quality of motor relaxation graded according to Bromage scale,

- total dosage of bupivacaine required,

- duration of analgesia

> Pulse rate, mean arterial pressure, arterial oxygen saturation was monitored for every 5 minutes in the initial 30 minutes of surgery, every 10 minutes in the next 1 hour of surgery and every 15 minutes for rest of the procedure. 
The quality of surgical analgesia:

- Excellent: No supplementary drug required

- Good: Supplementary analgesia required

- Fair: More than one analgesic required

- Poor: General anaesthesia required

\section{The Degree Of Motor Blockade Was Assessed}

According to Bromage scale:

- O: No paralysis (free movement of leg and feet, able to raise extended leg

- 1 : just able to flex knee with free movement of feet

- 2: inability to flex the knee, flexion of ankle and feet present

- 3: inability to flex the ankle joint, knee, raise leg

\section{Results}

The study population consisted of 60 patients posted for infra-umbilical and lower limbsurgeries. They were divided into two groups $\mathrm{C}$ and $\mathrm{E}$ of 30 each. Group (C) Patients were given subarachnoid block with 2.5 $\mathrm{ml}$ of $0.5 \%$ heavy bupivacaine initially following which Epidural Catheter was placed in situ at a separate intervertebral space.

The analgesic level obtained was checked and extended by administering $0.5 \%$ plain bupivacaine $1.5-2$ $\mathrm{ml} /$ unblocked segment required for surgical anesthesia. While Only Epidural block was given to group E patients with an in situ epidural catheter. Patient characteristics involved were age, sex and ASA grade. Bromage scale and level of sensory block at 2, 4, 6, 8 and 10 minutes was recorded.Pre-operative heart rate, blood pressure and respiratory rate were recorded prior to administering the block. Pulse rate, mean arterial pressure, arterial oxygen saturation was monitored for every 5 minutes in the initial 30 minutes of surgery, every 10 minutes in the next 1 hour of surgery and every 15 minutes for rest of the procedure.

The following observations were made during the course of the study. The patient characteristics are shown in Table 1. The average age of the patient was 52.9Yrs in group $\mathrm{C}$ and $46.3 \mathrm{Yrs}$ in group $\mathrm{E}$, the youngest being 14 and the oldest being $76 \mathrm{yrs}$ of age. The average weight of the patient was $70.4 \mathrm{kgs}$ in group $\mathrm{C}$ and $66.5 \mathrm{kgs}$ in group E.

Table No.3. Demographic data of study population.

\begin{tabular}{|l|l|l|l|}
\hline Parameters & Group C & Group E & P-value \\
\hline No. of patients & 30 & 30 & \\
\hline Age & $52.93 \pm 12.13$ & $46.30 \pm 12.39$ & $>0.05$ \\
\hline Weight $(\mathrm{kg})$ & $70.40 \pm 11.59$ & $66.50 \pm 12.17$ & $>0.05$ \\
\hline
\end{tabular}

The above table shows the demographic data pertaining to no. of patients, age and weight (in $\mathrm{kg}$ ). The column p-value shows there is no statistical significant in the distribution of age and weight of the patients in both the group.

Table No: 04. Shows gender distribution among both the group. Below cluster bar chart shows the same.

\begin{tabular}{|l|ll|}
\hline \multirow{2}{*}{ Sex } & Groups & \\
\cline { 2 - 3 } & C & E \\
\hline Male & 18 & 20 \\
Female & 12 & 10 \\
Total & 30 & 30 \\
\hline
\end{tabular}

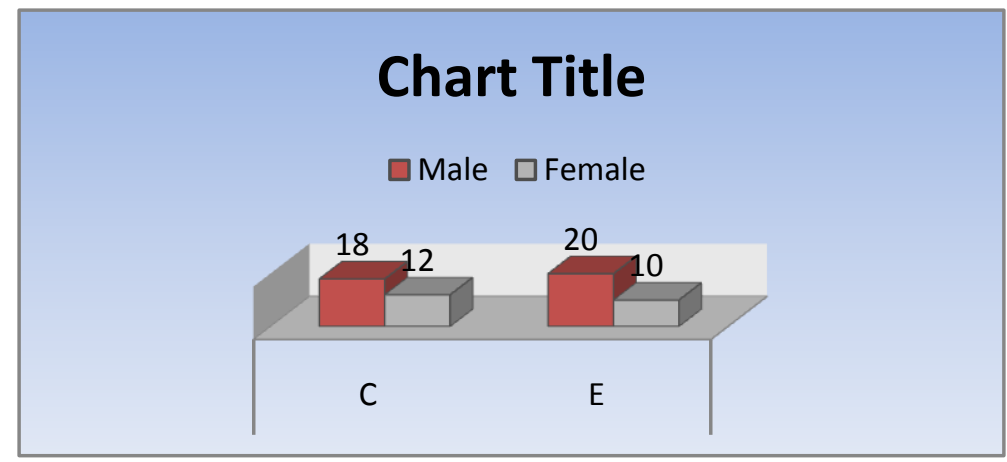


Fig 18: Sex wise distribution of study population.(A)

The study shows that among operated in the group $\mathrm{C}$ and $\mathrm{E}$ males were majority with $60 \%$ and $66.66 \%$ respectively.

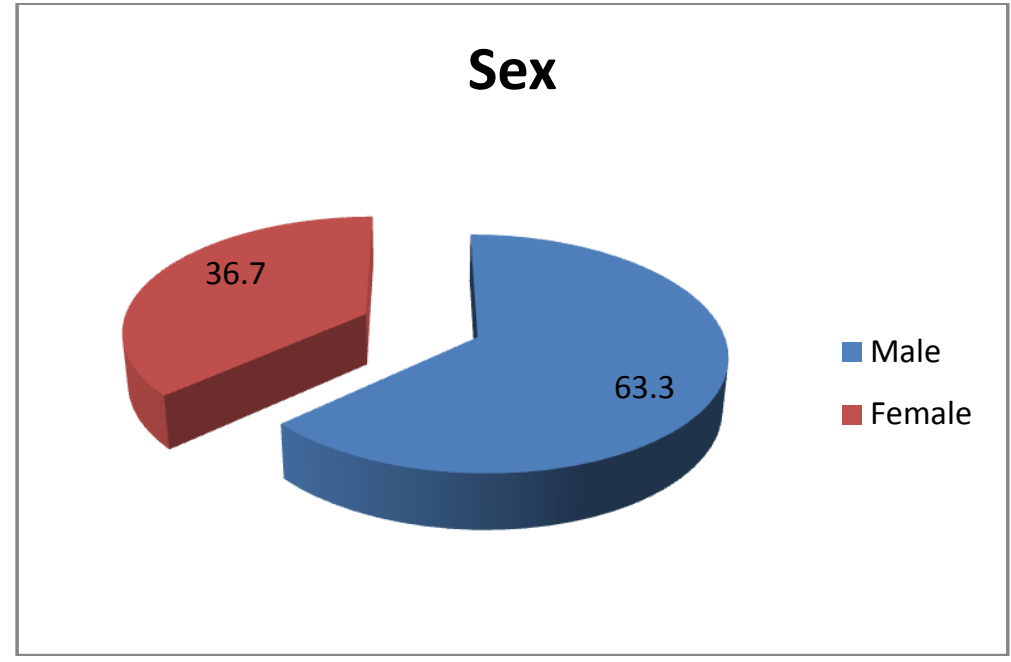

Fig 19: Sex wise distribution of study population.(B)

The study shows that among operated majority were males with $63.3 \%$ while the remaining $36.7 \%$ were females.

Table No: 5. Age wise distribution of the study sample in both the group. Below cluster sample shows the same.

\begin{tabular}{|l|l|l|l|l|}
\hline \multirow{2}{*}{ Age Group } & Group & \multirow{2}{*}{ Total } \\
\cline { 2 - 4 } \multicolumn{2}{|l|}{} & C & E & \\
\hline $11-20$. & 0 & 1 & 1 \\
\hline $21-30$ & 1 & 3 & 4 \\
\hline $31-40$ & 6 & 4 & 10 \\
\hline $41-50$ & 3 & 10 & 13 \\
\hline $51-60$ & 17 & 12 & 29 \\
\hline $61-70$ & 1 & 0 & 1 \\
\hline $71-80$ & 2 & 0 & 2 \\
\hline Total & 30 & 30 & 60 \\
\hline
\end{tabular}

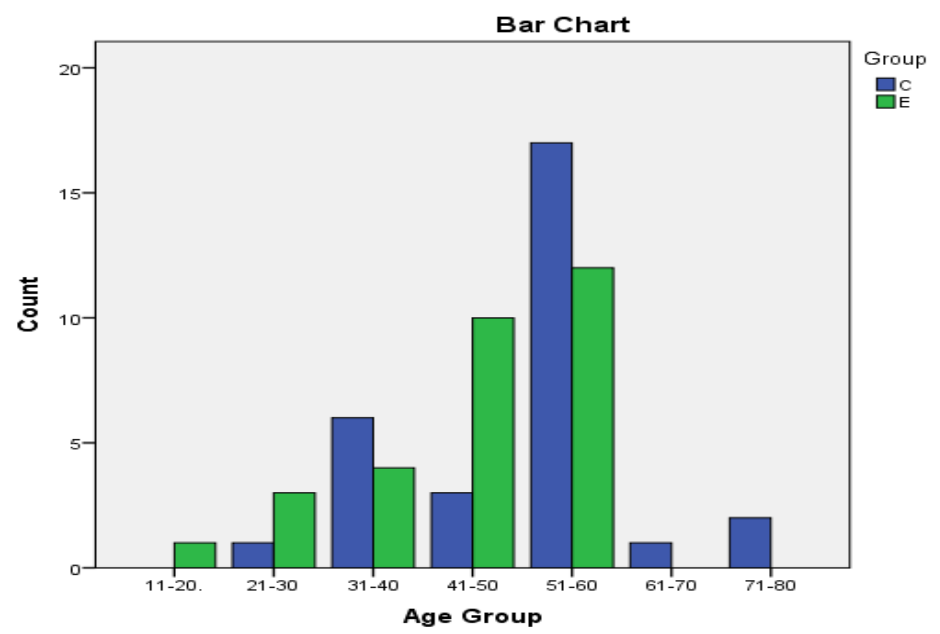

Fig 20: Age wise distribution of study population.

The above fig shows the age wise distribution of the study population which shows that majority in both of the groups were in the age group of 51-60 years and there were no cases below 20 years in $\mathrm{C}$ group while there were no cases above 60 years in E group. 
Study - “Comparative Study Of Combined Spinal Epidural Versus Epidural .......

Table 6 : The relationship between the two groups to Onset, Duration and Dosage of analgesic.

\begin{tabular}{|l|l|l|l|}
\hline Parameters & Group C & Group E & P-value \\
\hline Onset of Analgesia (min) & $8.30 \pm 6.35$ & $19.75 \pm 10.59$ & $<0.05$ \\
\hline $\begin{array}{l}\text { Duration of Analgesia } \\
\text { (min) }\end{array}$ & $79.83 \pm 4.63$ & $119.16 \pm 6.70$ & $<0.001$ \\
\hline $\begin{array}{l}\text { Total amount of } \\
\text { bupivacaine (mg) }\end{array}$ & $37.06 \pm 6.17$ & $117.96 \pm 6.61$ & $<0.001$ \\
\hline
\end{tabular}

Table No: 4. Show the mean onset time and duration of analgesia in group C is very significantly shorter than in group E with findings of $8.30 \pm 6.35$ mins and $19.75 \pm 10.59$ mins respectively. The total amount of bupivacaine required to reach at the same level was approximately 3 times in the group $\mathrm{E}$ as compared to group $\mathrm{C}$ which is statistically significant with $\mathrm{p}$ value $<0.001$.

Table 7: Relationship

\begin{tabular}{|l|l|l|l|}
\hline Quality & Group C & Group E & p-value \\
\hline Excellent & 22 & 11 & \\
\hline Good & 8 & 19 & $<\mathbf{0 . 0 0 1}$ \\
\hline Poor & 0 & 0 & \\
\hline Total & 30 & 30 & \\
\hline
\end{tabular}

of quality of analgesia between the two groups

It shows that majority of the patients who were given CSE had good quality of analgesia when compared to epidural route alone. This relationship is very significant in the $\mathrm{C}$ group with $\mathrm{p}$ value $<0.001$.

Table 8: Quality of relaxation post anaesthesia in both groups.

\begin{tabular}{|l|l|l|l|l|}
\hline \multirow{2}{*}{ Relaxation quality } & Group & \multirow{2}{*}{ Total } \\
\cline { 2 - 4 } & C & E & \\
\hline \multirow{2yyyn}{*}{1} & 0 & 21 & 21 \\
\hline 2 & 0 & 9 & 9 \\
\hline 3 & 30 & 0 & 30 \\
\hline \multicolumn{2}{|l|}{ Total } & 30 & 30 & 60 \\
\hline
\end{tabular}

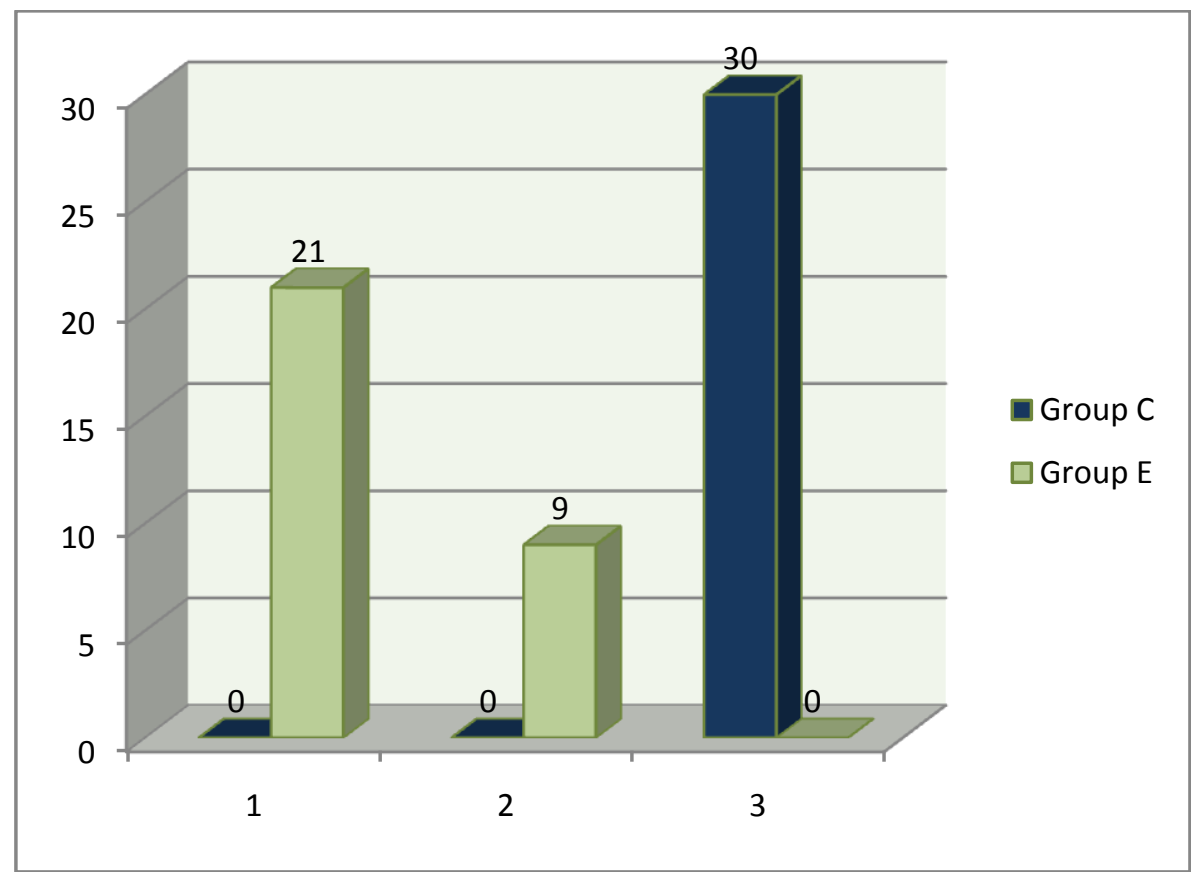

Fig 21: Quality of relaxation post anaesthesia in both groups.

\section{Inference}

Table No: 6 . Show the relaxation quality in both the group. All the patients in group C had grade 3 blockade as compared to none in group E. And almost $70 \%$ of the grade 1 blockade was seen in group E as compared to none in group C. Which signifies the superiority of CSE over Epidural alone. 
Study - "Comparative Study Of Combined Spinal Epidural Versus Epidural .......

Table No: 9. Hemodynamic change during anesthesia and surgery in both groups.

\begin{tabular}{|l|l|l|}
\hline Hemodynamic Parameters & Group C & Group E \\
\hline \% Fall in PR & & \\
\hline$<10$ & 3.2 & 4.9 \\
\hline $10-20$ & 1.9 & 1.7 \\
\hline $20-30$ & 0.3 & 0 \\
\hline$>30$ & 0 & 0 \\
\hline$\%$ Fall in Systolic BP & & \\
\hline$<10$ & 4.7 & 4.5 \\
\hline $10-20$ & 0.9 & 0.4 \\
\hline $20-30$ & 0.6 & 0 \\
\hline$>30$ & 0 & 0 \\
\hline
\end{tabular}

The above table shows that hemodynamic changes during anesthesia and surgery were comparable in both groups. Maximum number of patients in the group falls within $10 \%$ both in blood pressure and pulse rate and there weren't any changes above $30 \%$ in both the groups.

Table No: 10. The hemodynamic (systolic blood pressure) change during anesthesia in both the groups.

\begin{tabular}{|c|c|c|c|c|c|}
\hline Parameter & Group & $\mathrm{N}$ & Mean (Std. Deviation) & t-statistic & $\overline{p \text {-value }}$ \\
\hline \multirow[t]{2}{*}{ sbp_0 } & $\mathrm{C}$ & 30 & $126.26(11.96)$ & & \\
\hline & $\mathrm{E}$ & 30 & $125.63(10.34)$ & 0.219 & 0.827 \\
\hline \multirow[t]{2}{*}{ sbp_5 } & $\mathrm{C}$ & 30 & $121.30(13.11)$ & & \\
\hline & $\mathrm{E}$ & 30 & $119.40(8.77)$ & 0.660 & 0.512 \\
\hline \multirow[t]{2}{*}{ sbp_10 } & $\mathrm{C}$ & 30 & $112.66(11.88)$ & & \\
\hline & $\mathrm{E}$ & 30 & $108.50(10.71)$ & 1.426 & 0.159 \\
\hline \multirow[t]{2}{*}{ sbp_30 } & $\mathrm{C}$ & 30 & $112.50(8.19)$ & & \\
\hline & $\mathrm{E}$ & 30 & $114.36(5.46)$ & -1.038 & 0.303 \\
\hline \multirow[t]{2}{*}{ sbp_45 } & $\mathrm{C}$ & 30 & $115.20(8.65)$ & & \\
\hline & $\mathrm{E}$ & 30 & $116.33(6.42)$ & -0.576 & 0.567 \\
\hline \multirow[t]{2}{*}{ sbp_60 } & $\mathrm{C}$ & 30 & $115.86(9.47)$ & & \\
\hline & $\mathrm{E}$ & 30 & $114.36(6.06)$ & 0.730 & 0.468 \\
\hline \multirow[t]{2}{*}{ sbp_90 } & $\mathrm{C}$ & 30 & $115.06(9.08)$ & & \\
\hline & $\mathrm{E}$ & 30 & $119.20(4.32)$ & -2.250 & 0.028* \\
\hline \multirow[t]{2}{*}{ sbp_120 } & $\mathrm{C}$ & 30 & $118.10(7.20)$ & & \\
\hline & $\mathrm{E}$ & 30 & $120.70(6.34)$ & -1.483 & 0.143 \\
\hline \multirow[t]{2}{*}{ sbp_180 } & $\mathrm{C}$ & 30 & $119.93(6.39)$ & & \\
\hline & $\mathrm{E}$ & 30 & $124.03(6.18)$ & -2.524 & 0.014* \\
\hline \multirow[t]{2}{*}{ sbp_210 } & $\mathrm{C}$ & 10 & $121.70(6.36)$ & & \\
\hline & $\mathrm{E}$ & 11 & $123.18(4.79)$ & -0.607 & 0.551 \\
\hline \multirow[t]{2}{*}{$\operatorname{sbp} 240$} & $\mathrm{C}$ & 4 & $123.25(2.21)$ & & \\
\hline & $\mathrm{E}$ & 2 & $123.50(0.70)$ & -0.148 & 0.890 \\
\hline
\end{tabular}

Above table shows the hemodynamic (systolic blood pressure) change during anesthesia in both the groups. Overall p-value (almost all p>0.05) shows there no difference between the two groups which is statistically significant

Table No: 11. The hemodynamic (Diastolic blood pressure) change during anesthesia in both the groups.

\begin{tabular}{|c|c|c|c|c|c|}
\hline Parameter & Group & $\mathrm{N}$ & Mean (Std. Deviation) & t-statistic & p-value \\
\hline \multirow[t]{2}{*}{ dbp_0 } & $\mathrm{C}$ & 30 & $80.00(7.10)$ & & \\
\hline & $\mathrm{E}$ & 30 & $79.56(7.13)$ & 0.236 & 0.814 \\
\hline \multirow[t]{2}{*}{ dbp_5 } & $\mathrm{C}$ & 30 & $77.46(7.69)$ & & \\
\hline & $\mathrm{E}$ & 30 & $77.80(7.55)$ & -0.169 & 0.866 \\
\hline \multirow[t]{2}{*}{ dbp_10 } & $\mathrm{C}$ & 30 & $73.80(6.95)$ & & \\
\hline & $\mathrm{E}$ & 30 & $70.60(9.39)$ & 1.500 & 0.139 \\
\hline \multirow[t]{2}{*}{ dbp_30 } & $\mathrm{C}$ & 30 & $70.86(7.67)$ & & \\
\hline & $\mathrm{E}$ & 30 & $75.00(5.04)$ & -2.464 & 0.017 \\
\hline \multirow[t]{2}{*}{ dbp_45 } & $\mathrm{C}$ & 30 & $72.36(8.51)$ & & \\
\hline & $\mathrm{E}$ & 30 & $76.53(5.37)$ & -2.266 & 0.027 \\
\hline \multirow[t]{2}{*}{ dbp_60 } & $\mathrm{C}$ & 30 & $72.20(9.61)$ & & \\
\hline & $\mathrm{E}$ & 30 & $73.30(6.26)$ & -0.525 & 0.601 \\
\hline \multirow[t]{2}{*}{ dbp_90 } & $\mathrm{C}$ & 30 & $74.60(7.81)$ & & \\
\hline & $\mathrm{E}$ & 30 & $77.03(5.65)$ & -1.382 & 0.172 \\
\hline \multirow[t]{2}{*}{ dbp_120 } & $\mathrm{C}$ & 30 & $76.93(8.08)$ & & \\
\hline & $E$ & 30 & $76.70(6.90)$ & 0.120 & 0.905 \\
\hline \multirow[t]{2}{*}{ dbp_180 } & $\mathrm{C}$ & 30 & $75.70(6.42)$ & & \\
\hline & $E$ & 30 & $76.16(5.50)$ & -0.302 & 0.764 \\
\hline
\end{tabular}


Study - "Comparative Study Of Combined Spinal Epidural Versus Epidural .......

\begin{tabular}{|l|l|l|l|l|l|}
\hline \multirow{2}{*}{ dbp_210 } & C & 10 & $76.90(5.72)$ & & \\
\cline { 2 - 6 } & E & 11 & $76.63(6.46)$ & 0.098 & 0.923 \\
\hline \multirow{2}{*}{ dbp 240 } & C & 4 & $80.50(5.32)$ & & \\
\cline { 2 - 6 } & E & 2 & $69.50(0.70)$ & 2.747 & 0.052 \\
\hline
\end{tabular}

Above table shows the hemodynamic (Diastolic blood pressure) changes during anesthesia in both the groups. Overall p-values (almost all p>0.05) shows that there is no difference between the two groups which are statistically significant.

Table No: 12. The hemodynamic (Pulse rate) change during anesthesia in both the groups.

\begin{tabular}{|c|c|c|c|c|c|}
\hline Parameter & Group & $\mathrm{N}$ & Mean (Std. Deviation) & t-statistic & p-value \\
\hline \multirow[t]{2}{*}{$\overline{\text { pr_0 }}$} & $\mathrm{C}$ & 30 & $86.83(10.22)$ & \multirow[b]{2}{*}{2.963} & \multirow[b]{2}{*}{$0.004 *$} \\
\hline & E & 30 & $79.40(9.17)$ & & \\
\hline \multirow[t]{2}{*}{ pr_5 } & $\mathrm{C}$ & 30 & $81.90(11.88)$ & \multirow[b]{2}{*}{2.612} & \multirow[b]{2}{*}{0.011} \\
\hline & $\mathrm{E}$ & 30 & $75.00(8.25)$ & & \\
\hline \multirow[t]{2}{*}{ pr_10 } & $\mathrm{C}$ & 30 & $78.50(12.23)$ & \multirow[b]{2}{*}{2.618} & \multirow[b]{2}{*}{0.011} \\
\hline & $\bar{E}$ & 30 & $72.10(5.44)$ & & \\
\hline \multirow[t]{2}{*}{ pr_30 } & $\mathrm{C}$ & 30 & $70.86(8.94)$ & \multirow[b]{2}{*}{1.275} & \multirow[b]{2}{*}{0.207} \\
\hline & $\mathrm{E}$ & 30 & $68.60(3.84)$ & & \\
\hline \multirow[t]{2}{*}{ pr_60 } & $\bar{C}$ & 30 & $71.53(7.53)$ & \multirow[b]{2}{*}{2.349} & \multirow[b]{2}{*}{0.022} \\
\hline & $\mathrm{E}$ & 30 & $67.90(3.87)$ & & \\
\hline \multirow[t]{2}{*}{ pr_90 } & $\mathrm{C}$ & 30 & $70.46(7.12)$ & \multirow[b]{2}{*}{2.038} & \multirow[b]{2}{*}{$0.046^{*}$} \\
\hline & $\mathrm{E}$ & 30 & $67.46(3.76)$ & & \\
\hline \multirow[t]{2}{*}{ pr_120 } & $\mathrm{C}$ & 30 & $71.33(6.83)$ & \multirow[b]{2}{*}{3.097} & \multirow[b]{2}{*}{$0.003 *$} \\
\hline & $\mathrm{E}$ & 30 & $66.96(3.59)$ & & \\
\hline \multirow[t]{2}{*}{ pr_180 } & $\mathrm{C}$ & 30 & $72.23(6.33)$ & \multirow[b]{2}{*}{2.606} & \multirow[b]{2}{*}{$0.012 *$} \\
\hline & $\mathrm{E}$ & 30 & $68.60(4.25)$ & & \\
\hline \multirow[t]{2}{*}{ pr_210 } & $\mathrm{C}$ & 10 & $71.60(4.59)$ & \multirow[b]{2}{*}{1.507} & \multirow[b]{2}{*}{0.148} \\
\hline & $\bar{E}$ & 11 & $68.54(4.67)$ & & \\
\hline \multirow[t]{2}{*}{ pr 240} & $\mathrm{C}$ & 4 & $72.25(2.06)$ & \multirow[b]{2}{*}{-0.219} & \multirow[b]{2}{*}{0.838} \\
\hline & $\mathrm{E}$ & 2 & $73.00(7.07)$ & & \\
\hline
\end{tabular}

Above table shows the hemodynamic (Pulse rate) changes during anesthesia in both the groups. Overall p-values (almost all p>0.05) shows that there is no difference between the two groups which is statistically significant.

Table No: 13. The hemodynamic (mean respiratory rate) change during anesthesia in both the groups.

\begin{tabular}{|c|c|c|c|c|c|}
\hline Parameter & Group & $\mathrm{N}$ & Mean (Std. Deviation) & t-statistic & p-value \\
\hline \multirow[t]{2}{*}{ sp02_0 } & $\mathrm{C}$ & 30 & $99.43(0.56)$ & \multirow[b]{2}{*}{1.621} & \multirow[b]{2}{*}{0.110} \\
\hline & E & 30 & $99.16(0.69)$ & & \\
\hline \multirow[t]{2}{*}{ sp02_5 } & $\mathrm{C}$ & 30 & $99.56(0.50)$ & \multirow[b]{2}{*}{2.856} & \multirow[b]{2}{*}{$0.006 *$} \\
\hline & $\mathrm{E}$ & 30 & $99.03(0.88)$ & & \\
\hline \multirow[t]{2}{*}{ sp02_10 } & $\mathrm{C}$ & 30 & 99.66(0.47) & \multirow[b]{2}{*}{2.164} & \multirow[b]{2}{*}{0.035} \\
\hline & $\mathrm{E}$ & 30 & $99.30(0.79)$ & & \\
\hline \multirow[t]{2}{*}{ sp02_30 } & $\mathrm{C}$ & 30 & $99.60(0.62)$ & \multirow[b]{2}{*}{3.230} & \multirow[b]{2}{*}{$0.002 *$} \\
\hline & $\mathrm{E}$ & 30 & 98.93(0.94) & & \\
\hline sp02_45 & $\mathrm{C}$ & 30 & $99.63(0.61)$ & & \\
\hline
\end{tabular}


Study - “Comparative Study Of Combined Spinal Epidural Versus Epidural .......

\begin{tabular}{|c|c|c|c|c|c|}
\hline & $\mathrm{E}$ & 30 & $99.40(0.81)$ & 1.253 & 0.215 \\
\hline \multirow[t]{2}{*}{ sp02_60 } & $\mathrm{C}$ & 30 & 99.66(0.60) & \multirow[b]{2}{*}{1.829} & \multirow[b]{2}{*}{0.073} \\
\hline & $\mathrm{E}$ & 30 & $99.30(0.91)$ & & \\
\hline \multirow[t]{2}{*}{ sp02_90 } & $\mathrm{C}$ & 30 & $99.50(0.73)$ & \multirow[b]{2}{*}{1.861} & \multirow[b]{2}{*}{0.068} \\
\hline & $\mathrm{E}$ & 30 & $99.10(0.92)$ & & \\
\hline \multirow[t]{2}{*}{ sp02_120 } & $\mathrm{C}$ & 30 & $99.26(2.54)$ & \multirow[b]{2}{*}{0.068} & \multirow[b]{2}{*}{0.946} \\
\hline & $\mathrm{E}$ & 30 & $99.23(0.81)$ & & \\
\hline \multirow[t]{2}{*}{ sp02_180 } & $\mathrm{C}$ & 30 & $99.46(0.77)$ & \multirow[b]{2}{*}{0.965} & \multirow[b]{2}{*}{0.338} \\
\hline & $\bar{E}$ & 30 & $99.26(0.82)$ & & \\
\hline \multirow[t]{2}{*}{ sp02_210 } & $\mathrm{C}$ & 10 & $99.20(0.91)$ & \multirow[b]{2}{*}{0.253} & \multirow[b]{2}{*}{0.803} \\
\hline & $\mathrm{E}$ & 11 & $99.09(1.04)$ & & \\
\hline \multirow[t]{2}{*}{ sp02_240 } & $\mathrm{C}$ & 4 & $99.75(0.500)$ & \multirow[b]{2}{*}{2.000} & \multirow[b]{2}{*}{0.116} \\
\hline & $\mathrm{E}$ & 2 & $99.00(0.00)$ & & \\
\hline
\end{tabular}

Above table shows that, Mean respiratory rate changes during anesthesia in both the groups. Overall $\mathrm{p}$ values (almost all $\mathrm{p}>0.05$ ) shows there no difference between the two groups which are statistically significant.

\section{Discussion}

Introduction of spinal anaesthesia into clinical practice by August Bier and his assistant August. Hildebrandt in the year 1898 heralded a new era in providing anaesthesia for infra-umbilicaland lower limb surgeries, hitherto general anaesthesia was the only other alternative available.The first drug used intrathecally was cocaine. There were several side effects noted with theuse of cocaine like nausea, vomiting, dizziness, headache, restlessness and excitability tomention a few. These side effects were mitigated by the use of spinal opioids in combination withcocaine. With the introduction of bupivacaine, the first long acting amino amide into clinicalpractice in 1963, its use has been widespread.

CSE is an effective method to reduce the drug dosage used for anaesthesia, and choice of medication is based on concept of anti-nociceptive synergy (Ackerman et,1988). The subarachnoid injection allows rapid onset of analgesia with minimal dosage, flexibitly to extend the block depending upon the surgical incision required. In sequential CSE it is technically easy to spread the dermatomal distribution of the drug. The safety of CSE is enhanced by keeping a catheter insitu, thereby avoiding overshooting with regard to duration of spinal anaesthesia.

Many studies confirm that low dose local anesthetic and low dose opioid confer sufficient analgesia without any motor or proprioceptive impairment. This selective block render patient to bear weight and return to their casual routine even after any moderate to major surgery. In another words it hastens the recovery of surgical patients postoperatively.

In present study surgical analgesia and muscle relaxation following sequential CSE anaesthesia was better than those seen in epidural anaesthesia. The onset time for analgesia and motor blockade was shorter than epidural alone group. Various studies also observed the same result in the two groups, but mainly those studies are of foreign patients. The early onset and superior sensory and motor blockade of CSE may be due to the spinal component of CSE. The need for supplementary local anesthetics and sedatives were higher in patients receiving epidural anaesthesia alone. The incidence of epidural block failure is also high in group E.

Dosage requirement of bupivacaine in group $\mathrm{E}$ was about three to four times larger than group C. Priya gupta et $\mathrm{al}^{60}$ also observed the same pattern of dose requirement. In this study six patient did not need any epidural activation after CSE as they obtained adequate level after spinal itself. But nevertheless catheter was used for prudent postoperative analgesia.

1.The average age of the patients was 52.9Yrs in group $\mathrm{C}$ and $46.3 \mathrm{Yrs}$ in group E, the youngest being 14 and the oldest being 76 yrs. of age. The average weight of the patient was $70.4 \mathrm{kgs}$ in group $\mathrm{C}$ and $66.5 \mathrm{kgs}$ in group E. This finding is slightly higher when compared to the study conducted by Priya Gupta et al ${ }^{60}$ and lower age in the study conducted by Talikote et $\mathrm{al}^{61}$.

2.The age wise distribution of the study population which shows that majority in both of the groups were in the age group of 51-60 years and there were no cases below 20 years in $\mathrm{C}$ group while there were no cases above 60 years in E group. No studies were comparable to this finding.

3 . The mean onset time and duration of analgesia in group $\mathrm{C}$ is very significantly shorter than in group Ewith findings of $8.30 \pm 6.35 \mathrm{mins}$ and $19.75 \pm 10.59 \mathrm{mins}$ respectively. These findings were similar to 
Study - “Comparative Study Of Combined Spinal Epidural Versus Epidural .......

the findings of studies conducted by Priya Gupta et $\mathrm{al}^{60}$ and Talikote et $\mathrm{al}^{61}$. But the study conducted by Dr. Dipasri Bhattacharyaet $\mathrm{al}^{64}$ contradicts the findings.

4. The total amount of bupivacaine required to reach at the same level was approximately 3 times in the group $\mathrm{E}$ as compared to group $\mathrm{C}$ which is statistically significant with $\mathrm{p}$ value $<0.001$.These findings were similar to the findings of the study conducted by Priya Gupta et $\mathrm{al}^{60}$.

5. CSE allows reducing the local anesthetic intrathecal dosage up to $70 \%$, thus preserving sensory block quality, hemodynamic stability and providing rapid patient recovery, this finding is very similar to study conducted by Michele Cacciapaglia et al ${ }^{96}$.

In our study we found that majority of the patients who were given CSE had good quality of analgesia when compared to epidural route alone. This relationship is very significant in the $\mathrm{C}$ group with $\mathrm{p}$ value $<0.001$. This finding is in similar lines to the observations made in study conducted by Priya Gupta et al ${ }^{60}$, Talikote et $\mathrm{al}^{61}$ and Dr. Dipasri Bhattacharya ${ }^{64}$.

The study conducted by us revealed that the all the patients in group $\mathrm{C}$ had grade 3 blockade as compared to none in group E. And almost $70 \%$ of the grade 1 blockade was seen in group $\mathrm{E}$ as compared to none in group C. Which signifies the superiority of CSE over Epidural alone. This observation made is similar to the other studies conducted ${ }^{60,61,64}$.

The current study revealed thathemodynamic changes during anesthesia and surgery were comparable in both group. Maximum number of patients in the group falls within 10\% both in blood pressure and pulse rate and there weren't any changes above $30 \%$ in both the groups. This observation is similar to the study conducted by Talikote et $\mathrm{al}^{61}$ and contradictory to the observations seen in the study conducted by Priya Gupta et $\mathrm{al}^{60}$.

The hemodynamic changes such as systolic blood pressure, diastolic blood pressure, pulse rate and mean respiratory rate changes during anesthesia in both the groups shows that there no difference between the two groups with $p$ value $>0.05$. Similar observations were made in other studies conducted by others ${ }^{60,61}$.

In this study identification of epidural space was done by loss of resistance, syringe technique, this technique being easy and less complicated than others such as hanging drop technique, capillary tube technique, manometer technique, ultrasonic technique. Separate needle and separate interspace technique was used to perform subarachnoid block and to keep epidural catheter insitu. This technique is better than single interspace technique in sense of chances of spinal needle shearing the epidural catheter.

Local anesthetic injected into epidural space acts on the dorsal root ganglia and spinal roots with their dural cuffs in the extradural space.

1. Leakage by vascular absorption

2. Leakage through intervertebral foramina

3. Diffusion through dural root sleeves

4. Diffusion through dura matter

5. Drug flux from epidural to subarachnoid space

After drug administration in epidural space, there is transient rise in epidural pressure which is generally lower than subarachnoid, this transient rise may causelittle amount of drug flux into subarachnoid space through the dural hole. Drug flux depends more on the size of hole than physiochemical property of the drug. Unidentified accidental dural puncture with epidural needle is hazardous in means of local anesthetic toxicity, catheter migration or misplacement should always kept in mind.

CSE being multicompartement block is complicated when compared to epidural alone or spinal alone. But when performed carefully it can provide best anaesthesia compared to other techniques in terms of fast onset, low drug usage, flexibitly of blockade, duration of analgesia and postoperative pain management. Adding epidural volume after spinal blockade enhances and modify spinal effects and provide better level of blockade compared to either of the techniques. Brownidge's first report of CSE in obstetric anaesthesia described epidural catheter placement at L1-L2 followed by subarachnoid block at L3-L4. This allowed epidural catheter to be tested and placed before subarachnoid block was initiated which is not possible with needle through needle technique. Disadvantage of this technique is patient has to experience double needle prick, but this confers safe technique when compared to single interspace technique as chances of spinal needle shearing of epidural catheter is much less. Main disadvantage when subarachnoid block is initiated before epidural catheter placement is, hyperbaric solution and positioning delay may lead to saddle block or unilateral block, also delay in giving test dose and interpretation of intravascular catheterization is difficult, rendering double needle different interspace technique a user-friendly and easy technique.

In this study complication like postdural puncture headache, transient neurological symptoms, epidural hematoma, nerve injury, total or high spinal was not reported which was much similar to finding to study of Priyanka C gupta et $\mathrm{al}^{60}$. 
Study - “Comparative Study Of Combined Spinal Epidural Versus Epidural .......

Combined Spinal Epidural Anaesthesia (CSE) combines two techniques instead of drugs which has greater efficacy \& cost effectiveness. The benefit of this technique lies in its ability to combine the rapidity, density, and reliability of the subarachnoid block with the flexibility of continuous epidural block to titrate a desired sensory level, vary the intensity of the block, control the duration of anesthesia, and deliver postoperative analgesia.

Its use is extended to pediatric and even infant laparotomies, apart from its use in orthopedic surgery, obstetrics, and very old patients and in other high-risk patients. ${ }^{6}$ CSE technique is safer than other in old debilated patients as degree of hypotension is lower \& slower in onset, beside low degree of motor blockade helps early discharge $\&$ help to fasten up the new concept of day care surgery.

Recently, the combined spinal-epidural technique has gained popularity in labor analgesia. This technique offers some benefits including faster onset of analgesia, decreased incidence of motor blockade, more reliable technique, higher level of patient satisfaction, and decreased incidence of accidental dural puncture ${ }^{8}$.

Spinal addition of opioids, alone or in combination with bupivacaine, has been associated with high levels of pruritus $(>80 \%),{ }^{9}$ hypotension $(20 \%)$, and respiratory depression. ${ }^{10}$ It also may cause fetal bradycardia. ${ }^{11}$ Placental transfer is rapid whether the opioid is given by intravenous ( $5 \mathrm{~min})$, epidural (>15 min), or intrathecal bolus $(>15 \mathrm{~min}) .^{12}$ The ideal dose of intrathecal Sufentanil in addition to a low dose of local anesthetic (LA) varies between $1.5 \mu \mathrm{g}$ and $5 \mu \mathrm{g} .3,{ }^{13}$ With Neurological and Adaptive Capacity Scores (NACS), the effects of intrapartum drugs on the neonate can be observed. ${ }^{14}$

For major orthopedic surgery such as total hip or knee arthroplasty, regional anesthesia has been shown to have several advantages over general anesthesia. ${ }^{15,16,17}$ In a controlled study comparing CSE, spinal anesthesia and epidural block for orthopedic surgery, it was shown that spinal anesthesia and CSE were superior to epidural block. ${ }^{17}$ CSA is a well-established technique that has been used successfully in many surgical procedures.

In literature several data suggest that the intrathecal local anesthetic dose can be reduced by executing a sequential block with the epidural extension performed within 5 or 10 minutes of the intrathecal injection, leading to less hypotension and quicker recovery ${ }^{6,18 .}$ The combined sequential spinal epidural (CSSE) technique has been studied mostly for cesarean section, and it may be advantageous as well in other high-risk patients such as very old urologic patients, by increasing the safety of the central regional block ${ }^{6,19,20,21,22}$

Doses and concentrations of local anesthetic used for CSSE are of great importance in determining the clinical management of this technique, and local anesthetic pharmacodynamics and pharmacokinetic profile can influence CSSE outcome: recently Levobupivacaine emerged in regional anesthesia as a safer alternative to other local anesthetics, including its racemic parent bupivacaine, since it demonstrated less affinity and reduced depressant effects onto myocardial and central nervous vital centers in pharmacodynamics studies, and a superior pharmacokinetic profile ${ }^{23}$. Actually, CSSE with intrathecal dose of bupivacaine as low as $5 \mathrm{mg}$ has been found to allow good surgical anesthesia in cesarean delivery ${ }^{24}$.

However, Bonicaoutlined various reasons for not-so-frequent use of regionalanesthesia, surgeon \& patient disliking was one of them ${ }^{25}$.Since surgeons are integral part of health care providing team, measuring their satisfaction with a particularanesthetic technique would enhance the quality of anesthesiapractice as well as indirectly improving patient satisfactionrate.However, use of CSE anesthesia or analgesia also introduces the potential for complications, such as technical failure, altered spread of epidural drugs in patients who also had a lumbar puncture, and altered spread of subarachnoid medications due to the effects of the epidural injection. ${ }^{27}$

Although various other methods are available for postoperative \& intraoperative analgesia, such as pharmacological \& regional blocks. Use of high dose of pain medication endangers the patient vital organs such as renal and liver and also increases the total cost of delivering prudent anaesthesia. Use of more recent technique such as lumbar block, celiac block, paracervical block is more technically challenging and further requirement of higher imaging techniques for identifying the anatomy is difficult in many setting, especially in our country. Therefore, CSE technique need further study in Indian patients in order to have a depth of understanding that in which surgeries and in which patients will be benefited. Which made us to take up this study to compare CSE \& Epidural block alone in terms of onset and duration of surgical analgesia.

\section{Summary}

A randomized double blinded controlled clinical study was conducted over a period of $11 / 2$ years from October 2014 to April 2016 in the Department of Anesthesiology on Patients coming to SVMCH \&RC for surgical procedures lasting up to 3 hours. The quality of surgical analgesia by pinprick method, quality of motor relaxation graded according to bromage scale, total dosage of bupivacaine required, duration of analgesia \& various hemodynamicchanges was noted in comparison with both the procedures. The study revealed the following The average age of the patient was 52.9Yrs in group $\mathrm{C}$ and 46.3 Yrs in group $\mathrm{E}$, the youngest being 14 and the oldest being $76 \mathrm{yrs}$ of age. The average weight of the patient was $70.4 \mathrm{kgs}$ in group $\mathrm{C}$ and $66.5 \mathrm{kgs}$ in group E. 
* The study resultsshow that among operated in the group C and E males were majority with $60 \%$ and $66.66 \%$ respectively.

* Majority in both of the groups were in the age group of 51-60 years and there were no cases below 20 years in $\mathrm{C}$ group while there were no cases above 60 years in $\mathrm{E}$ group.

* The mean onset time and duration of analgesia in group $\mathrm{C}$ is very significantly shorter than in group E.

* The total amount of bupivacaine required to reach at the same level was approximately 3 times in the group $\mathrm{E}$ as compared to group $\mathrm{C}$ which is statistically significant with $\mathrm{p}$ value $<0.001$.

* Majority of the patients who were given CSE had good quality of analgesia when compared to epidural route alone. This relationship is very significant in the $C$ group with $p$ value $<0.001$.

* All the patients in group $\mathrm{C}$ had grade 3 blockade as compared to none in group E. And almost $70 \%$ of the grade 1 blockade was seen in group $\mathrm{E}$ as compared to none in group $\mathrm{C}$. Which signifies the superiority of CSE over Epidural alone

* Heamodynamic change during anesthesia and surgery were comparable in both group. Maximum number of patients in the group falls within $10 \%$ both in blood pressure and pulse rate and there weren't any changes above $30 \%$ in both the groups.

* Systolic blood pressure change during anesthesia in both the groups shows overall p-value (almost all $\mathrm{p}>0.05)$ shows there no difference between the two groups which is statistically significant

* Diastolic blood pressure changes during anesthesia shows that overall p-values (almost all p $>0.05$ ) there is no difference between the two groups which are statistically significant.

* Pulse rate changes during anesthesia in both the groupsshows that there is no difference between the two groups which is statistically significant with overall $p$-values (almost all $\mathrm{p}>0.05$ )

* Mean respiratory rate changes during anesthesia in both the groupsshows that there no difference between the two groups which are statistically significant with overall $\mathrm{p}$-values (almost all $\mathrm{p}>0.05$ )

\section{Conclusion}

In conclusion, CSE is found to be better andsuperior alternative to epidural block. Advantagesoffered by CSE are faster onset of action, superiorquality of analgesia, better muscle relaxation and lessdose of local anaesthetic required to reach the same level(Sequential CSE). The incidence and severity ofhypotension and bradycardia is similar with both theblocks. The duration of analgesia by two segmentregression method needs to be further analyzed. ThusCSE offers the best of both spinal and epidural techniqueand has a promising future in regional anaesthesia.

\section{Bibliography}

[1]. The International Association for the Study of Pain's. Derived from http://www.iasp-pain.org/Taxonomy last accessed on 16/8/16.

[2]. Datta S, Alper MH, Ostheimer GW, Weiss JB. Method of ephedrine administration and nausea and hypotension during spinal anesthesia for cesarean section. Anesthesiology 1982; 56: 68-70.

[3]. Thorburn J, Moir DD. Bupivacaine toxicity in association with extradural analgesia for caesarean section. Br J. Anaesth 1984; 56: 551-553.

[4]. Soresi AL. Episubdural anesthesia. Anesth Analg 1937; 16:306-10.

[5]. Curelaru I. Long duration subarachnoid anesthesia with continuous epidural blocks. Praktische Anaesthesie Wiederbelebung und Intensive therapie .1979; 14:71-8.

[6]. Rawal N, Holmstrom B, Crowhurst JA, Van Zundert A. The combined spinal-epidural technique. Anesthesiol Clin North America. 2000; 18: 267-95.

[7]. Simmons SW, Cyna AM, Dennis AT, Hughes D . Combined spinal-epidural versus epidural analgesia in labour. 2007;Cochrane Database Syst Rev CD003401.

[8]. Collis RE, Davies DWL, Aveling W. Randomised comparison of combined spinal-epidural and standard epidural analgesia in labour. Lancet. 1995; 345: 1413-6.

[9]. Harsten A, Gillberg L, Hakansson L, Olsson M. Intrathecal sufentanil compared with epidural bupivacaine analgesia in labor. Eur J Anaesthesiol.1997; 14:642-5.

[10]. Hays RL, Palmer CM. Respiratory depression after intrathecal sufentanil during labor. Anesthesiology. 1994; 81: 511-2.

[11]. Cohen SE, Cherry CM, Holbrook H Jr, El-Sayed YY, Gibson RN, Jaffe RA. Intrathecal sufentanil for labor analgesia-sensory changes, side effects, and fetal heart rate changes. Anesth Analg. 1993;77: 1155-60.

[12]. Helbo-Hansen HS. Neonatal effects of maternally administered fentanyl, alfentanil and sufentanil. Baillieres Clin Anaesthesiol. 1995; 9: 675-89.

[13]. Camann W, Abouleish A, Eisenach J, Hood D, Datta S. Intrathecal sufentanil and epidural bupivacaine for labor analgesia: doseresponse of individual agents and in combination. Reg Anesth Pain Med. 1998; 23:457-62.

[14]. Amiel-Tison C, Barrier G, Shnider SM, Levinsin G, Hughes SC, Steafni SJ. A new neurologic and adaptive capacity scoring system for evaluating obstetric medications in full-term newborns. Anesthesiology. 1982;56:340-50.

[15]. Modig J, Hjelmestedt A, Sahlstedt B, Maripuu E. Comparative influences of epidural and general anaesthesia on deep venous thrombosis and pulmonary embolism after total hip replacement. Acta Chir Scand. 1981;147(2):125-30.

[16]. Rosberg B, Fredin H, Gustafson C. Anesthetic techniques and surgical blood loss in total hip arthroplasty. Acta Anaesthesiol Scand. 1982;26(3):189-93.

[17]. Holmström B, Laugaland K, Rawal N, Hallberg S. Combined spinal epidural block versus spinal and epidural block for orthopaedic surgery. Can J Anaesth. 1993;40(7):601-6.

[18]. Bevacqua BK . Continuous spinal anaesthesia: what's new and what's not. Best Pract Res Clin Anaesthesiol. 2003;17: 393-406. 
[19]. Choi DH, Ahn HJ, Kim JA. Combined low-dose spinal-epidural anesthesia versus single-shot spinal anesthesia for elective cesarean delivery. Int J Obstet Anesth. 2006; 15: 13-17.

[20]. Lim Y, Teoh W, Sia AT . Combined spinal epidural does not cause a higher sensory block than single shot spinal technique for cesarean delivery in laboring women. Anesth Analg. 2006; 103: 1540-42.

[21]. Lew E, Yeo SW, Thomas E. Combined spinal-epidural anesthesia using epidural volume extension leads to faster motor recovery after elective cesarean delivery: a prospective, randomized, double-blind study. Anesth Analg. 2004; 98: 810-14.

[22]. Teoh WH, Thomas E, Tan HM .Ultra-low dose combined spinal-epidural anesthesia with intrathecal bupivacaine $3.75 \mathrm{mg}$ for cesarean delivery: a randomized controlled trial. Int J Obstet Anesth . 2006;15: 273-78.

[23]. Huang YF, Pryor ME, Mather LE, Veering BT .Cardiovascular and central nervous system effects of intravenous levobupivacaine and bupivacaine in sheep. Anesth Analg. 1998; 86: 797-804.

[24]. Ben-David B, Miller G, Gavriel R, Gurevitch A . Low-dose bupivacaine-fentanyl spinal anesthesia for cesarean delivery. Reg Anesth Pain Med. 2000; 25: 235-39.

[25]. Bonica JJ. Regional anesthesia in private practice. Anesthesiology 1960;21:554-6.

[26]. N Swarnkar, A Ghosh, A Yadav. Sequential Combined Spinal Epidural Block Superior To Epidural Block For Total Abdominal Hysterectomy In Patient And Surgeons Perspective: Double Blind Randomized Control Trial. The InternetJournal of Anesthesiology. 2007;18( 2)

[27]. Stamenkovic, D., V. Geric, M. Djordjevic, J. Raskovic, Z. Slavkovic, T. Randjelovic, and M.Karanikolas. Subarachnoid morphine, bupivacaine and fentanyl as part of combined spinal-epidural analgesia for low anterior resection. A prospective randomised double-blind clinical trial: Anaesth.Intensive Care. 2009; 37( 4), 552- 60.

[28]. Corning, JL. Spinal anesthesia and local medication of the cord. N Y Med J. 1885;42:483

[29]. Parkin IG \& Harrison GR. The topographical anatomy of the lumbar epidural space.Journal of Anatomy. 1985;141: 211-17.

[30]. Nickallis RWD , Kokri MS. The width of posterior epidural space in obstetricpatients. Anaesthesia. 1986;41:432-33.

[31]. Mackintosh, RR.; \& Lee, JA. Lumbar puncture and spinal analgesia. ChurchillLivingstone. 1973; 3rd ed. ISBN 0-443-00997-X

[32]. Bromage PR. Epidural analgesia. 1978; Philadelphia: WB Saunders: 191-96.

[33]. Husemeyer RP \& White DC. Topography of the lumbar epidural space. A study in cadavers using injected polyester resin. Anaesthesia, 1980; 35: 7-11.

[34]. Hogan QH. Epidural anatomy: new observations. Can J Anaesth. 1998; 45: 40-48.

[35]. Dogliotti AM. . Research and clinical observations on spinal anaesthesia: with specialreference to the peridural technique. Anesthesia \& Analgesia. 1933; 12: 59-65.

[36]. Lai HC, Liu TJ, Peng SK, Lee KC, Luk HN \& Lee SC. Depth of the thoracic epiduralspace in paramedian approach. J Clin Anaesth. 2005; 17: 339-43

[37]. Ravi KK, Kaul TK, Kathuria S, Gupta S \& Khurana S.Distance from skin to epidural space: Correlation with body mass index (BMI). J Anaesthesiol Clin Pharm. 2011; 27: 39-42.

[38]. Corning JL. Spinal anaesthesia and local medication of the cord. NY Med J. 1885;42:483-485.

[39]. Wynter WE. Lumbar puncture. Lancet 1891;1:981-982

[40]. Quincke HI. Die technik der lumbalpunktion. Verh Dtsch Ges Inn Med 1891;10:321-331

[41]. Von Ziemssen HW. Allgemeine behandlung der infektionskrankenheiten. Jena 1894

[42]. Bier A. Versuche uber Cocainisirung des Ruckenmarkes. Dtsch Ztschr Chir 1899;51:361-69.

[43]. Zaric D, Christiansen C, Pace NL, et al. Transient neurologic symptoms after spinalanesthesia with lidocaine versus other local anesthetics: A systematic review ofrandomized, controlled trials. Anesth Analg 2005; 100:1811-16.

[44]. Keld DB, Hein L, Dalgaard M, et al. The incidence of transient neurologic symptomsafter spinal anaesthesia in patients undergoing surgery in the supine position. Hyperbariclidocaine 5\% versus hyperbaric bupivacaine 0.5\%. Acta Anaesthesiol Scand. 2000; 44:285-290.

[45]. Sakura S, Sumi M, Sakaguchi Y, et al. The addition of phenylephrine contributes to thedevelopment of transient neurologic symptoms after spinal anesthesia with $0.5 \%$ tetracaine. Anesthesiology .1997; 87:771-778.

[46]. Liguori GA, Zayas VM, Chisholm MF: Transient neurologic symptoms after spinalanesthesia with mepivacaine and lidocaine. Anesthesiology .1998; 88:619-23.

[47]. Urmey, W. F. Combined spinal epidural anesthesia: Techniques in regional anesthesia\& pain management. 2000;4( 1):13-18

[48]. Urmey, W. F., J. Stanton, M. Peterson, and N. E. Sharrock. Combined spinal-epidural anesthesia for outpatient surgery. Doseresponse characteristics of intrathecal isobaric lidocaine using a 27-gauge Whitacre spinal needle. Anesthesiology. 1995; 83(3): 528-34.

[49]. Urmey, W. F., J. Stanton, N. E. Sharrock, and E. Nigel. Combined Spinal/Epidural Anesthesia for Outpatient Surgery. Anesthesiology.1996; 84(2): 481-82.

[50]. Rosenberg, P. H. Novel technology: needles, microcatheters, and combined techniques: Reg Anesth.Pain Med.1998; 23(4): 363 69.

[51]. Kopacz, D. J, B. G. Bainton. Combined spinal epidural anesthesia: a new "hanging drop".Anesth.Analg.1996; 82(2): 433-34.

[52]. Cook T. M. Combined spinal-epidural techniques. Anaesthesia.2000; 55 (1): $42-64$.

[53]. Turner, M. A., N. A. Reifenberg. Combined spinal epidural anaesthesia: the singlespace double-barrel technique. Int.J.Obstet.Anesth. 1995; 4(3): 158-60.

[54]. Cook, T. M. Combined spinal-epidurals for anaesthesia using a separate needleTechnique. Eur.J.Anaesthesiol. 2004; 21(9): 679-83

[55]. Rawal, N., Z. A. Van, B. Holmstrom, and J. A. Crowhurst. Combined spinal-epiduralTechnique. Reg Anesth. 1997; 22( 5): 406-23.

[56]. Eldor, J. The evolution of combined spinal-epidural anesthesia needles: Reg Anesth.1997; 22(3): 294-96.

[57]. Puolakka, R., M. T. Pitkanen, and P. H. Rosenberg.Comparison of technical and blockcharacteristics of different combined spinal and epidural anesthesia techniques. Reg Anesth.Pain Med. 2001; 26(1): 17-23.

[58]. Dahl, J. B., J. Rosenberg, W. E. Dirkes, T. Mogensen, and H. Kehlet.Prevention ofpostoperative pain by balanced analgesia. Br.J.Anaesth. 1990; 64(4): 518-20.

[59]. Vercauteren, M. P., K. Geernaert, D. M. Vandeput, and H. Adriaensen. Combinedcontinuous spinal-epidural anaesthesia with a single interspace, double-catheter technique: Anaesthesia. 1993; 48(11): 1002-04.

[60]. Priya gupta , C. K. Dua , U. C. Verma , K. N. Saxena and Indranil Chakraborty .Sequential combined spinal epidural versus epidural anaesthesia in Orthopaedic and Gynaecological Surgery: A comparative evaluation. Indian J Anaesth 2002;46(6) : 453-56.

[61]. Talikota N, Muntha B, Thatisetti PV. Comparison of Effi cacy and Safety of Sequential Combined Spinal EpiduralTechnique and Spinal Block for Lower Abdominal Surgeries: A Randomized Controlled Trial. Int J Sci Stud 2015;3(4):25-30.

[62]. Luiz Eduardo Imbelloni, Marildo Assunção Gouveia, José Antonio Cordeiro . Continuous spinal anesthesia versus combined spinal epidural block for major orthopedic surgery: prospective randomized study.Sao Paulo Med J. 2009; 127(1):7-11. 
[63]. Tyagi A, Kumar A, Sethi AK and Mohta M. Epidural volume extension and intrathecal dose requirement: plain versus hyperbaric bupivacaine. Anesth Analg. 2008 Jul;107(1):333-8.

[64]. Bhattacharya, Tewari, Chowdhuri .Sequential CSEA vs. SA in high risk geriatric patients. Indian J. Anaesth. $2007 ; 51$ (1) : 32 - 36

[65]. Amit G Bhagwat ,C K Dua, Kirti N Saxena, Srikant Srinivasan, Kanika Dua.Combined spinal epidural and low dose epidural in progress of labour. Indian J Anaesth. 2008; 52 (3):282-87.

[66]. Michael P. Nageotte. David Larson, Pamela,J. Rumney, Mohan Sidhu and Katherine Hollenbach. Epidural analgesia compared with Combined Spinal-Epidural Analgesia during labor in nulliparous women. The New England Journal of Medicine.1997; 337(24):1715-19.

[67]. Ng K, Parsons J, Cyna AM, Middleton P. Spinal versus epidural anaesthesia for caesarean section. Cochrane Database of Systematic Reviews .2004; 2 .

[68]. Butterworth JF, Strichartz GR. Molecular mechanism of local anesthesia-A review.Anesthesiology. 1990; 72:722-34.

[69]. Lee-Son S, Nang GK, Concus A et al. Stereo selective inhibition of neuronal sodiumchannels by local anesthetics: Evidence for two sights for action?.Anesthesiology, 1992;77; 324-35.

[70]. A Chandra Sekhar Reddy. Randomized Double Blinded Controlled study of Ropivacaine versus Bupivacaine in Combined Spinal Epidural Anaesthesia. From dissertation submitted to the Pondicherry University, Pondicherry.2011.

[71]. Rothstein P, Cole J, Pih BR. Pulmonary extraction of bupivacaine is dose dependent. Anesthesiology .1984; 61;236.

[72]. Pihlajamaki K, Kantro J, Lindberg R et al. Extradural administration of bupivacaine:Pharmacokinetics and metabolism in pregnant and non pregnant women. Br J Anesth .1990; 64:556-62.

[73]. Duncan L, Wildsmith JAW. Liposomal local anesthetics. Br J Anesth .1995; 75:260-61.

[74]. Brown DT, Beamish D, Wildsmith JAW. Allergic reaction to an amide local anesthetic.Br J Anesth 1981; 53:435-37.

[75]. Covino BG, Vassallo HC. Local anesthesia, mechanism of action and clinical use.NewYork: Grune and Stratton, 1976.

[76]. Albright GA. Cardiac arrest following regional anesthesia with etidocaine or bupivacaine. Anesthesiology 1979; 51:285-87.

[77]. Timour Q, Fuys N, Coazon P et al. Possible role of drug interactions, bupivacaine induced problems related to intraventricular conduction disorder. Reg Anesth 1990; 15: 180-85.

[78]. Roitman K, Sprung J, Wallace M et al. Enhancement of bupivacaine cardio toxicity withcardiac glycosides and beta adrenergic blockers-A case report. Anesth Analg.1993; 76: 658-61.

[79]. Atlee Jl, Bosnjak ZL. Mechanism of dysrhythmias during anesthesia. Anesthesiology .1990; 72:347-74.

[80]. Kendig JJ. Clinical implications of the modulated receptor hypothesis; local anesthetics and the heart. Anesthesiology .1985; 62:382-84

[81]. Kasten GW, Martin ST. Bupivacaine cardiovascular toxicity. Comparison of treatment with Bretylium and lidocaine. Anesth Analg 1985; 64:914-16

[82]. Boogaerts J, Decdercq A, Lafont $\mathrm{N}$ et al. Toxicity for bupivacaine encapsulated into liposomes and injected IV: comparison with plain solutions. Anesth Analg 1993; 76:553- 55.

[83]. Picard j, Meek T. Lipid emulsion to treat overdose of local anesthetic, the gift of the globe. Anesthesia. 2006; 61:107-09.

[84]. Rosenblatt MA, Abel M, Fischer GW et al. Successful use of a $20 \%$ lipid emulsion to resuscitate a patient after a presumed bupivacaine related cardiac arrest. Anesthesiology .2006; 105:217-18.

[85]. Hiller A, Rosenberg PH. Transient neurological symptoms after spinal anesthesia with $4 \%$ mepivacaine and $0.5 \%$ bupivacaine. Br $\mathbf{J}$ Anesth .1997; 79:301-05.

[86]. Akio J, Yoshitomi A, Kohji N et al. Local anesthetics inhibit priming of neutrophils bylipopolysaccharide for enhanced release of superoxides: suppression of cytochrome b 558expression by disparate mechanism. Journal of leukocyte biology .2005; 78:1356-65.

[87]. Millan MJ. Descending control of pain. Prog Neurobiol. 2002;66(6):355-474.

[88]. Meyer RA, Ringkamp M, Campbell JN, et al. Peripheral neural mechanisms of nociception.In: McMahon SB, Koltzenburg M, editors. Wall and Melzack's texbook of pain. 5th edition.Philadelphia: Elsevier Limited; 2006;3-34.

[89]. Guilbaud G, Besson J-M. Physiologie du circuit de la douleur. In: Brasseur L, Chauvin M,Guilbaud G, editors. Douleurs. Paris: Maloine; 1997; 7-22.

[90]. Levine J, Taiwo Y. Inflammatory pain. In: Wall PD, Melzack R, editors. Texbook of pain. New York: Chruchill Livingston; 1994;45-56.

[91]. Marchand S. Le phe'nome`ne de la douleur. Montre’ al (Canada): Chenelie`re McGraw-Hill et Masson; $1998 ; 311$.

[92]. Byers MR, Bonica JJ. Peripheral pain mechanisms and nociceptor plasticity. In: Loeser JD, editor. Management of pain. New York: Lippincott Williams \& Wilkins; 2001;26-72.

[93]. Serge Marchand. The Physiology of Pain Mechanisms: From the Periphery to the Brain. Rheum Dis Clin N Am . 2008;34: 285309.

[94]. Coghill RC, Talbot JD, Evans AC, et al. Distributed processing of pain and vibration by the human brain. J Neurosci 1994;14(7):4095-108.

[95]. Talbot JD, Marrett S, Evans AC, et al. Multiple representations of pain in human cerebralcortex. Science .1991;251(4999):1355-8.

[96]. Cacciapaglia M, Cinnella G, Schiraldi R, Cormio L, Vetuschi P, et al. Combined Sequential Spinal Epidural Anesthesia: A Prospective Study. J Anesth Clin Res 2012; 3:232. doi:10.4172/2155-6148.1000232

List Of Contents

\begin{tabular}{||l|l|l|}
\hline Sl. No. & Topic & Page No. \\
\hline 1. & Introduction & $1-3$ \\
\hline 2. & Aim \& Objectives & 4 \\
\hline 3. & Review of literature & $5-55$ \\
\hline 4. & Materials \& Methods & $56-59$ \\
\hline 5. & RESULTS & $60-78$ \\
\hline 6 & DISCUSSION & $79-88$ \\
\hline 7 & Summary & $89-90$ \\
\hline 8 & conclusion & 91 \\
\hline 9 & REFERENCES & $92-103$ \\
\hline 10 & Annexures & 104 \\
\hline
\end{tabular}




\section{List Of Tables}

\begin{tabular}{|l|l|l|}
\hline $\begin{array}{l}\text { SL. } \\
\text { NO }\end{array}$ & \multicolumn{1}{|c|}{ TITLES } & PAGE NO \\
\hline 1 & Uses of CSE in surgical practice & 20 \\
\hline 2 & Types of nerve fibers carrying pain & 49 \\
\hline 3 & Demographic data of study population & 61 \\
\hline 4 & Gender wise distribution of the study population & 62 \\
\hline 5 & Age wise distribution of the study population & 63 \\
\hline 6 & $\begin{array}{l}\text { The relationship between the two groups to Onset, Duration } \\
\text { and Dosage of analgesic }\end{array}$ & 66 \\
\hline 7 & $\begin{array}{l}\text { Relationship of quality of analgesia between the two groups } \\
\text { Quality of relaxation post anaesthesia in both groups }\end{array}$ & 67 \\
\hline 9 & $\begin{array}{l}\text { Hemodynamic change during anesthesia and surgery in both } \\
\text { groups }\end{array}$ & 70 \\
\hline 10 & $\begin{array}{l}\text { The hemodynamic (systolic blood pressure) change during } \\
\text { anesthesia in both the groups. }\end{array}$ & 71 \\
\hline 11 & $\begin{array}{l}\text { The hemodynamic (Diastolic blood pressure) change during } \\
\text { anesthesia in both the groups. }\end{array}$ & 72 \\
\hline 12 & $\begin{array}{l}\text { The hemodynamic (Pulse rate) change during anesthesia in } \\
\text { both the groups. }\end{array}$ & 75 \\
\hline $\begin{array}{l}\text { The hemodynamic (mean respiratory rate) change during } \\
\text { anesthesia in both the groups. }\end{array}$ & 77 \\
\hline
\end{tabular}

\section{List Of Figures}

\begin{tabular}{|c|c|c|}
\hline Sl.No & Titles & Page No \\
\hline 1 & Anatomy Of Lumbar Spine. & 8 \\
\hline 2 & Anatomy Of Lumbar Vertebra. & 8 \\
\hline 3 & Transverse Section Of Lumbar Vertebra. & 14 \\
\hline 4 & Sagittal Section Of Lumbar Region. & 15 \\
\hline 5 & Transverse Section Of Lumbar Region At L1 & 16 \\
\hline 6 & Needle-Through-Needle Technique & 21 \\
\hline 7 & Special Single Cse Needles. & 23 \\
\hline 8 & Chemical Formula Bupivacaine. & 31 \\
\hline 9 & Commercial Form Of Bupivacaine. & 31 \\
\hline 10 & Epidural Kit & 45 \\
\hline 11 & Combined Spinal Epidural Kit & 45 \\
\hline 12 & Quincke Spinal Needle & 46 \\
\hline 13 & Nociceptive Signal Pathways & 48 \\
\hline 14 & Conduction Among The Various Nerve Fibres & 50 \\
\hline 15 & $\begin{array}{l}\text { Transmission Among The Nerve Fibres In The } \\
\text { Physiology Of Pain.(A) }\end{array}$ & 51 \\
\hline 16 & $\begin{array}{l}\text { Transmission Among The Nerve Fibres In The } \\
\text { Physiology Of Pain.(B) }\end{array}$ & 52 \\
\hline 17 & Endogenous Pain Modulation. & 54 \\
\hline 18 & Sex Wise Distribution Of Study Population.(A) & 62 \\
\hline 19 & Sex Wise Distribution Of Study Population.(B) & 63 \\
\hline 20 & Age Wise Distribution Of Study Population. & 65 \\
\hline 21 & $\begin{array}{l}\text { Quality Of Relaxation Post Anaesthesia In Both } \\
\text { Groups }\end{array}$ & 68 \\
\hline
\end{tabular}

